\title{
ENSINO DA DISCIPLINA DE CONTABILIDADE GERAL EM CURSOS DE GRADUAÇÃO EM ADMINISTRAÇÃO: UMA ANÁLISE EMPÍRICA DA RELAÇÃO ENTRE A SATISFAÇÃO E O DESEMPENHO DISCENTE
}

\author{
Tatiane Silva Carmo 1 \\ João Carlos Hipólito Bernardes do Nascimento 2 \\ Flávia Lorenne Sampaio Barbosa ${ }^{3}$ \\ Maurício Mendes Boavista de Castro ${ }^{4}$
}

- Artigo recebido em: 15/01/2019 -- Artigo aceito em: 20/02/2020 -.' Segunda versão aceita em: 20/03/2020

\section{RESUMO}

Os conhecimentos contábeis são essenciais para o administrador na execução de suas funções, uma vez que capacita os profissionais para atuarem em contextos competitivos e permeados de constantes mudanças. Nessa perspectiva, o presente estudo buscou investigar, empiricamente, a relação entre a satisfação dos alunos de graduação em Administração, acerca da disciplina de Contabilidade Geral, e o desempenho, auto reportado, obtido nesta disciplina. Para alcançar esse objetivo, realizou-se uma survey com 528 discentes do $3^{a}$ ao $8^{\circ}$ período de sete Instituições de Ensino Superior, públicas e privadas, das cidades de Floriano-PI, Teresina-PI, Picos-PI e Parnaíba-PI que ofertam o curso de graduação em Administração presencialmente, utilizando, para coleta de dados, o questionário proposto por Paswan e Young (2002) e adaptado ao contexto brasileiro por Beuren, Cunha, Theiss, \& Cordeiro (2013). Quanto aos resultados, foram obtidos indícios empíricos que possibilitaram validar a proposta de modelar a "Satisfação Discente" como um construto de segunda ordem, sendo notado, que, o "envolvimento do professor" mostrou-se o construto mais relevante, dentre os investigados, para explicar a satisfação discente. Adicionalmente, observou-se que a "Satisfação Discente" apresenta uma relação direta e positiva no rendimento acadêmico auto reportado $(\beta=0,128$;

\footnotetext{
' Bacharela em Administração de Empresas. Endereço: Universidade Federal do Piauí (UFPI), Campus Amilcar Ferreira Sobral, BR-343, KM 3,5 - Meladão, Floriano - PI, 64808-605. E-mail: thaty.rosa36@gmail.com.

2 Doutor em Ciências Contábeis. Endereço: Universidade Federal do Piauí (UFPI), Campus Universitário Ministro Petrônio Portella s/n, Centro de Ciências Humanas e Letras - CCHL/UFPI, Coordenação do Curso de Ciências Contábeis - Ininga, Teresina - Pl, 64049-550. E-mail: joaohipolito@ufpi.edu.br.
}

http://orcid.org/0000-0003-3505-372X

3 Doutora em Administração de Empresas. Endereço: Universidade Federal do Piauí (UFPI), Campus Amilcar Ferreira Sobral, BR-343, KM 3,5 - Meladão, Floriano - PI, 64808-605. E-mail: flsbarbosa@hotmail.com. https://orcid.org/0000-0002-4804-9538

${ }^{4}$ Doutor em Ciências Empresariais -. Endereço: Universidade Federal do Piauí (UFPI), Campus Universitário Ministro Petrônio Portella s/n, Centro de Ciências Humanas e Letras - CCHL/UFPI, Coordenação do Curso de Administração de Empresas- Ininga, Teresina - Pl, 64049-550. E-mail: mauricioboavista@ufpi.edu.br.

https://orcid.org/0000-0002-8463-1197 
$p<0,001)$, independentemente do efeito das variáveis de controle gênero, idade, período do curso e instituição de ensino. Esses achados mostram-se relevantes ao contribuir para a discussão e análise das peculiaridades e carências no ensino das disciplinas de Contabilidade no curso de Administração, possibilitando que os coordenadores e docentes repensem e proponham ações para a otimização do ensino de Contabilidade para não contadores.

Palavras-Chave: Graduação em Administração. Ensino de Contabilidade Geral. Satisfação Discente. Desempenho Acadêmico.

\title{
TEACHING OF THE GENERAL ACCOUNTING DISCIPLINE IN GRADUATION COURSES IN ADMINISTRATION: AN EMPIRICAL ANALYSIS OF THE RELATIONSHIP BETWEEN STUDENT SATISFACTION AND PERFORMANCE
}

\begin{abstract}
Accounting skills are essential for the administrator in the execution of his duties, since it enables the professionals to act in competitive contexts and permeated by constant changes. In this perspective, the present study sought to investigate, empirically, the relation between the satisfaction of the undergraduate students in Administration, about the General Accounting discipline, and the performance, self reported, obtained in this discipline. To achieve this goal, a survey was conducted with 528 students from the 3rd to 8th period of seven Public and Private Higher Education Institutions of the cities of Floriano-PI, Teresina-PI, Picos-PI and Parnaíba-PI offering a questionnaire proposed by Paswan and Young (2002) and adapted to the Brazilian context by Beuren et al. (2013). As for the results, empirical evidence was obtained that allowed validating the proposal of modeling "Student Satisfaction" as a second-order construct. It was noted that "teacher involvement" was the most relevant construct among the investigated, to explain student satisfaction. In addition, it was observed that "Student Satisfaction" presents a direct and positive relationship in self-reported academic performance $(\beta=0.128$; $p<0.001$ ), regardless of the effect of control variables gender, age, course period and educational institution. These findings are relevant when contributing to the discussion and analysis of the peculiarities and deficiencies in the teaching of the Accounting disciplines in the Administration course, allowing the coordinators and teachers to rethink and propose actions for the optimization of Accounting teaching to non-accountants.
\end{abstract}

Keywords: Degree in administration. General Accounting Teaching. Student Satisfaction. Academic achievement.

\section{INTRODUÇÃO}

Na era do conhecimento, a informação é crucial em qualquer segmento, assim, emerge a necessidade de promover uma educação interdisciplinar nos campos de profissionalização e formação acadêmica. No ambiente organizacional, cujo contexto está em constante mudança, essa tendência faz- 
Ensino da Disciplina de Contabilidade Geral em Cursos de Graduação em Administração: uma Análise Empírica da Relação entre a Satisfação e o Desempenho Discente

se ainda mais necessária, tendo em vista que a Administração é uma ciência interdisciplinar com interface em várias áreas de conhecimento como Psicologia, Antropologia, Sociologia, Economia, Ciências Contábeis, Direito, entre outras (Alves, Teixeira, \& Oliveira, 2017).

Nessa perspectiva, a interdisciplinaridade assume papel de fundamental relevância no ensino de Administração, uma vez que capacita os profissionais para atuarem em contextos competitivos e permeados de constantes mudanças (Borges, \& Mafra, 2013). Essa demanda (de interdisciplinaridade) é oficialmente assegurada pela Resolução $n^{\circ} 4$ de 13 de julho de 2005, que determina as Diretrizes Curriculares Nacionais do Curso de Graduação em Administração, em nível de bacharelado, que dispõe sobre os quesitos norteadores da estrutura curricular a ser seguida pelas Instituições de Ensino Superior (Raupp, Amboni, Cunha, Duarte, \& Agostineto, 2009).

A norma legal supracitada determina o ensino da Contabilidade como obrigatório na graduação de Administração, visto que fornece informações relevantes na tomada de decisões, habilitando o administrador para conhecer e, sobretudo, interpretar os relatórios contábeis para fins de tomada de decisão (Raupp et al., 2009). Nessa perspectiva, a Contabilidade mostra-se de fundamental importância para o exercício profissional do administrador no momento em que revela-se um instrumento de auxílio à gestão de negócios, imprescindível para a mensuração do desempenho, controle do patrimônio, sendo, nesse aspecto, um eficaz sistema de informação que abrange os mais diversos níveis de gestão, além de mostrar-se um instrumento de comunicação da organização com todos os usuários da informação contábil (Costa, Alves, Rocha, \& Ramos, 2011).

A importância dos conhecimentos contábeis no campo da Administração e da interdisciplinaridade no processo de ensino-aprendizagem são ressaltadas por vários autores (Bianchi, Raimundini, Santos, Fávero, \& Schmidt, 2010; Costa et al., 2011; Crispim, \& Miranda, 2013; Borges, \& Mafra, 2013), no entanto, é recorrente na literatura a discussão acerca da melhor forma de ensino das disciplinas de Contabilidade no curso de Administração: se com foco na operacionalização do débito e crédito; ou na análise das demonstrações contábeis (Vasconcelos, 2000; Iudicibus, \& Marion, 2009; Raupp et al., 2009; Crispin, \& Miranda, 2012). No ensejo, alguns esforços empíricos buscando aprofundar essa discussão foram conduzidos no Brasil nos últimos anos. Costa et al. (2011), com uma amostra composta por 157 discentes do curso de Administração, concluíram que os alunos, além de atribuírem importância elevada da Contabilidade para a formação acadêmica/profissional, sentem uma dificuldade moderada nas disciplinas de Contabilidade, apresentando, no entanto, nível de autoconfiança intermediário quanto ao domínio dos fundamentos teóricos, dos métodos e das técnicas contábeis.

Crispim e Miranda (2013), com uma amostra mais robusta (586 acadêmicos de Administração), constataram que a metodologia adotada pelo corpo docente enfatiza o débito e o crédito, criando, assim, uma aversão dos alunos de administração no tocante às disciplinas de contabilidade. Mais recentemente, Borges e Mafra (2013), com uma amostra composta por 261 graduandos em Administração, concluíram que os discentes compreendem relativamente bem o que é ensinado na sala de aula nas disciplinas de Contabilidade, mas, no 
entanto, não se sentem suficientemente seguros diante das avaliações e da prática (dos conhecimentos contábeis) dentro das organizações.

No entanto, embora a percepção de relevância de determinada disciplina para a formação acadêmica/profissional seja um aspecto importante no aprendizado dos conteúdos ministrados (Santos, Mognon, Lima, \& Cunha, 2011), não foram notados estudos específicos que buscassem relacionar a satisfação, por parte dos discentes de graduação em Administração, acerca da disciplina de Contabilidade Geral, frente ao desempenho, auto reportado, obtido nessa disciplina, lacuna, esta, explorada na presente pesquisa.

Assim, considerando que existe, na literatura, uma discussão não consensual acerca da melhor forma de ensino das disciplinas de Contabilidade no curso de Administração (se com foco na operacionalização do débito e crédito; ou na análise as demonstrações contábeis) e que o seu aprendizado se faz obrigatório e relevante para a formação discente, propõe-se investigar o seguinte problema de pesquisa: Qual a relação entre satisfação e o desempenho discente na disciplina de Contabilidade Geral, no curso de graduação em Administração? Para tanto, parte-se do pressuposto de que, fatores satisfatórios concernentes ao processo ensino-aprendizado nessa disciplina, possivelmente, refletirão, com êxito, no resultado avaliativo final (nota) apresentado.

Nessa linha, o presente estudo buscou, a título de objetivo geral, investigar a relação entre a satisfação dos discentes de graduação em Administração, acerca da disciplina de Contabilidade Geral, e o desempenho, auto reportado, obtido nessa disciplina. E, secundariamente: (1) identificar o perfil dos discentes frente aos construtos de primeira ordem definidos para o estudo; (2) modelar a "satisfação discente" como construto de segunda ordem, e, por fim, (3) avaliar a relação direta entre satisfação discente e o desempenho auto reportado.

Para tal, foi conduzida uma survey com 528 (quinhentos e vinte e oito) discentes do terceiro ao oitavo períodos do curso de graduação em Administração de Empresas de 7 (sete) Instituições de Ensino Superior (públicas e privadas) das cidades de Floriano-PI, Teresina-PI, Picos-PI e Parnaíba-PI que ofertam o curso presencialmente.

Como instrumento de coleta de dados, foi aplicado um questionário formado por dois blocos: o primeiro abordando informações descritivas; e o segundo compreendendo 0 instrumento de coleta de dados proposto por Paswan e Young (2002) e adaptado ao contexto brasileiro por Beuren et al. (2013), que modela a satisfação discente na perspectiva do "envolvimento do professor em sala de aula", "interesse do aluno", "interação professor/aluno", "demandas da disciplina" e "organização da disciplina". Adicionalmente, dado o objetivo do presente estudo, foi adicionado um item específico para capturar o desempenho, auto reportado, obtido pelos discentes na disciplina de Contabilidade Geral.

Utilizou-se, como técnica de análise dos dados, a Modelagem de Equações Estruturais (MEE) na abordagem de Mínimos Quadrados Parciais (Partial least squares structural equation modeling - PLS-SEM) dado o enquadramento essencialmente exploratório do presente estudo (uma vez que é proposto e testado um modelo estrutural em que a "Satisfação Discente" é modelada como 
Ensino da Disciplina de Contabilidade Geral em Cursos de Graduação em Administração: uma Análise Empírica da Relação entre a Satisfação e o Desempenho Discente

um construto de segunda ordem, o que, no conhecimento dos autores, é uma iniciativa inédita na literatura).

Considerando que a Resolução no 4 de 13 de julho de 2005 do Conselho Nacional de Educação, que trata das Diretrizes Curriculares Nacionais do Curso de Graduação em Administração, determina o ensino da Contabilidade como obrigatório na graduação de Administração, sendo, nesse aspecto, estas disciplinas imprescindíveis para a formação discente, o estudo proposto mostrase relevante ao abordar um relacionamento pouco explorado pela literatura empírica na área de gestão, no conhecimento dos autores, isto é, a relação entre desempenho acadêmico frente a satisfação discente acerca das disciplinas de Contabilidade, em especial, da Contabilidade Geral.

Ademais, a exemplo de Borges e Mafra (2013), Crispim e Miranda (2013), Raupp et al. (2009) e Alves, Teixeira e Oliveira (2017), o presente estudo tem o potencial de contribuir com a identificação de aspectos que eventualmente necessitam de melhorias, de acordo com a satisfação discente, sobretudo no tocante às diferentes possibilidades de abordagens das disciplinas de Contabilidade nos cursos de Administração.

\section{FUNDAMENTAÇÃO TEÓRICA}

\subsection{Breve Contextualização do Ensino de Contabilidade para não Contadores}

Em um contexto de globalização, de importantes avanços tecnológicos e das constantes modificações do ambiente empresarial, a educação interdisciplinar é necessária atualmente em várias áreas de formação. Especificamente na formação do administrador, esta demanda é indiscutivelmente necessária, visto que a Administração é genuinamente interdisciplinar (Borges, \& Naves, 2014).

A resolução $n^{\circ} 4$ de 13 de julho de 2005, que determina as Diretrizes Curriculares Nacionais do Curso de Graduação em Administração em nível de bacharelado, e dispõe sobre os quesitos norteadores da estrutura curricular a ser seguida pelas Instituições de Ensino Superior, indica os seguintes conteúdos da formação em Administração: conteúdos de formação básica; conteúdos de formação profissional; conteúdos de estudos quantitativos e suas tecnologias; e conteúdo de formação complementar.

Especificamente acerca da Contabilidade, esta é compreendida nos conteúdos de formação básica, que se relacionam com "estudos antropológicos, sociológicos, filosóficos, psicológicos, ético-profissionais, políticos, comportamentais, econômicos e contábeis, bem como os relacionados com as tecnologias da comunicação e da informação e das ciências jurídicas" (Brasil, 2005, p. 27).

Conforme a referida norma legal, a oferta de disciplinas de Contabilidade é obrigatória na graduação em Administração, sendo seus conhecimentos imprescindíveis para o embasamento do Administrador, instrumentalizando o profissional para interpretar os relatórios contábeis, tais como o Balanço Patrimonial, a Demonstração do Resultado do Exercício, a Demonstração do Fluxo de Caixa, a Demonstração do Valor Adicionado e a Demonstração das Mutações do Patrimônio Líquido (ludícibus, \& Marion, 2009). 
Nessa perspectiva, a Contabilidade suporta a tomada de decisão, além de possibilitar avaliar a adequação das decisões tomadas pelos gestores, seja no tocante a investimento ou na capacitação de recursos. Crispim e Miranda (2012) enfatizam a importância da Contabilidade para o Administrador destacando que esta fornece registros das operações realizadas pelas empresas, auxiliando a análise e a interpretação dos gastos efetuados.

Na formação do administrador, geralmente, o ensino da Contabilidade é iniciado até o terceiro semestre do curso, sendo que, entre as disciplinas mais frequentes, pode-se citar: Contabilidade Geral, Contabilidade de Custos, Análise de Balanços e Contabilidade Tributária (Borges, \& Naves, 2014; Alves, Teixeira, \& Oliveira, 2017).

Borges e Mafra (2013) afirmam que o ensino de Contabilidade para não contadores é um assunto ainda pouco abordado em publicações, que, mais recentemente, ainda que de forma tímida, vem sendo abordado em artigos internacionais, trabalhos de Dissertação, artigos, periódicos e eventos nacionais. Quanto à bibliografia, ludícibus e Marion (2009) relatam que os livros ou materiais básicos de Contabilidade existentes no Brasil são muito bons, mas, no entanto, geralmente têm um enfoque voltado especificamente para graduandos em Contabilidade, isto é, são escassas as obras específicas para não contadores.

Os profissionais que necessitam dos conhecimentos contábeis no exercício de suas profissões utilizam-nos de acordo com suas necessidades, que variam de uma área para outra. No entanto, geralmente, as disciplinas de Contabilidade ministradas em cursos de áreas afins ensinam os mesmos conteúdos ministrados para os graduandos em Ciências Contábeis, não atendendo, assim, a real necessidade dos não contadores (Vasconcelos, 2000). Iudícibus e Marion (2009) nesse aspecto, enfatizam que, na formação dos não contadores, o foco deveria ser dado aos Relatórios Contábeis e à sua interpretação, isto é, com ênfase nos aspectos gerenciais e decisório que os relatórios gerados pela contabilidade podem oferecer, e não especificamente (como normalmente ocorre) na operacionalização do débito e crédito.

Diante do exposto, os docentes devem, na medida do possível, ajustar a ênfase que, muitas vezes, é dada na operacionalização da Contabilidade (em como fazer), para focarem efetivamente interpretação (para o que serve), obedecendo, assim, os objetivos estipulados pela Resolução n 4, de 13 de julho de 2005 do Conselho Nacional de Educação (Crispim, \& Miranda, 2012).

A grade curricular do Curso de Administração deve estar sempre se atualizando, de forma que as disciplinas ofertadas atendam às necessidades dos administradores para um bom desempenho profissional (Santos,2015). No tocante ao ensino de Contabilidade para não contadores, Raupp et al. (2009) explicitam que o administrador, na sua formação, não necessita de teorias e estudos complexos em Contabilidade, mas de foco naquilo que é primordial para o desenvolvimento da carreira.

\subsection{Breve Contextualização sobre Abordagens de Ensino em Contabilidade}

Conforme apresentado anteriormente, as disciplinas de Contabilidade estão presentes na grade curricular de muitos cursos, tais como Direito, Engenharia e Economia, melhor capacitando estes profissionais para atuarem no 
Ensino da Disciplina de Contabilidade Geral em Cursos de Graduação em Administração: uma Análise Empírica da Relação entre a Satisfação e o Desempenho Discente

atual mercado competitivo (Raupp et al., 2009). Nesta perspectiva, por se tratar de público variado com comportamento e formas distintas de aprendizagem e, sobretudo, de aplicação dos conhecimentos obtidos de Contabilidade, os docentes que ministram estas disciplinas devem utilizar metodologias variadas de forma a possibilitar maior interesse e aprendizado, facilitando, assim, a compreensão dos conteúdos ministrados, otimizando, assim, o processo de ensino-aprendizagem (Neves Júnior, \& Rocha, 2010).

Crispim e Miranda (2012) relatam que as metodologias de ensino utilizadas nas salas de aula pelos docentes são de fundamental importância para a efetividade do processo de aprendizagem, tendo em vista que estas influenciam diretamente no comportamento dos discentes diante dos conteúdos ministrados. Nérici (2006) faz uma distinção entre método e técnica, destacando que o método "é o caminho para se alcançar os objetivos estabelecidos em um planejamento de ensino, enquanto que a técnica demonstra como fazer algo".

Diante destas definições, Neves Júnior e Rocha (2010) apresentam as metodologias de ensino mais utilizadas no processo de ensino-aprendizagem em Contabilidade. As aulas expositivas e a resolução de exercícios são as metodologias mais práticas e utilizadas no cotidiano das salas de aula do ensino em Contabilidade, no entanto, se os docentes não utilizarem métodos diversificados corre-se o risco dos discentes dispersarem a atenção, não alcançando, assim, um bom aproveitamento dos conteúdos trabalhados (Neves Júnior, \& Rocha, 2010).

Conforme Neves Júnior e Rocha (2010) os seminários, dissertações ou resumos e estudo dirigido ou aulas orientadas tendem a levar os alunos a pesquisarem, aprofundando-se nos conteúdos e, inclusive, possibilitando a estes expressarem seus conhecimentos sobre o tema. No entanto, para que essas metodologias de ensino sejam efetivamente motivadoras, é necessário que o tema em estudo seja relevante na satisfação do aluno.

As excursões ou visitas técnicas e os jogos de empresas podem mostrar-se bastante motivadoras e importantes para os discentes no momento em que aproximam a teoria da prática, levando-os a vivenciarem um pouco da realidade das organizações (Crispim, \& Miranda, 2012). Neves Júnior e Rocha (2010) afirmam ainda que o estudo de caso, a utilização de laboratórios e oficinas em geral, tendem a despertar o interesse dos acadêmicos, tendo em vista que possibilitam pôr em prática a teoria ao simular problemas reais. Essas últimas estratégias, em especial, tendem a preparar melhor os alunos para lidarem com problemas do cotidiano das empresas. As palestras, grupos de discussão e debate, no geral, também tendem a mostrar-se motivadoras e proveitosas, pois tratam de conteúdo diferentes e relevantes para a formação do graduando, possibilitando a confrontação e discussão de diversificadas visões (Neves Júnior, \& Rocha, 2010).

Em sua pesquisa realizada na Universidade Comunitária da Região de Chapecó, com alunos e professores do Curso de Graduação em Ciências Contábeis, Brighenti, Biavatti e Souza (2015) identificaram a satisfação dos alunos referente aos métodos, técnicas e recursos utilizados no processo de ensinoaprendizagem. Os autores notaram que, quanto à metodologia de ensino utilizada, a maioria dos alunos consideraram como muito eficaz para a aprendizagem a resolução de exercícios (84\%) e a realização de aulas mistas 
(teórica e prática 77\%). Dentre as técnicas e métodos mais utilizados pelos professores estão as aulas expositivas (87\%), seguida da realização de simulados e provas (89\%) (Brighenti, Biavatti, \& Souza, 2015).

Em relação aos recursos utilizados, os discentes consideram como muito eficaz para a aprendizagem a utilização de livros e apostilas (58\%) e a utilização de recursos multimídias, como filmes/vídeos (62\%). No entanto, na percepção dos alunos, os recursos mais corriqueiramente utilizados pelos professores são: apresentações em data show (84\%); apostilas e livros (65\%); sendo as leituras complementares utilizadas com menor intensidade (Brighenti, Biavatti, \& Souza, 2015).

\subsection{Estudos Empíricos sobre o Ensino de Contabilidade}

Nessa etapa do estudo, foram analisados alguns dos principais os estudos empíricos nacionais que investigaram o ensino de Contabilidade. Utilizando a técnica multivariada de MEE e uma versão adaptada do instrumento de pesquisa proposto por Paswan e Young (2002), Vieira, Milach e Huppes (2008) investigaram os determinantes da satisfação geral dos alunos do curso de Ciências Contábeis da Universidade Federal de Santa Maria (UFSM). Entre os principais achados, os autores concluíram que modelo ajustado mostrou-se adequado para mensurar a satisfação geral dos estudantes.

Raupp et al. (2009) identificaram os tópicos, os conteúdos, as metodologias de ensino e de verificação de aprendizagem e os livros mais utilizados no ensino de Contabilidade Geral e Contabilidade de Custos nos cursos de graduação em Administração do Estado de Santa Catarina. Os estudos de Bianchi et al. (2010) contataram que há relação entre as categorias estudadas (instituições de ensino, docentes e os cursos) e algumas variáveis características discente, tais como; idade, origem dos discentes quanto ao ensino médio, e turno em que é cursada a disciplina de Contabilidade.

Costa et al. (2011) obtiveram indícios empíricos de que os acadêmicos apresentam interesse apenas moderado pela área contábil, mas, no entanto, consideram a área imprescindível para sua formação. Os autores perceberam, também, que alguns fatores influenciam o interesse dos discentes, como a autoconfiança e a importância percebida. Azevedo et al. (2012) notaram que há um importante interesse dos estudantes de administração pela área de contabilidade e finanças, sendo que alguns fatores interferem nesse interesse, sobretudo, o interesse pessoal na área de Finanças e a qualidade docente sob a ótica discente, entre outros.

Utilizando-se da entropia informacional, Beuren et al. (2013) mapearam a visão de discentes de diferentes cursos (Administração, Ciências Contábeis, Ciências Econômicas, Tecnólogo em Comércio Exterior, Turismo e Sistemas de Informação) fundamentados no modelo proposto por Paswan e Young (2002), que avalia a percepção discente sobre a disciplina de Contabilidade Introdutória em cinco perspectivas: "Envolvimento do professor"; "Envolvimento de estudante"; "Interação estudante-professor"; "Demanda da disciplina"; e "Organização da disciplina".

Segundo Beuren et al. (2013), o constructo "Envolvimento do Professor" compreende questões relacionadas com o comportamento do professor em sala

112 Revista Contabilidade Vista \& Revista, ISSN 0103-734X, Universidade Federal de Minas Gerais, Belo Horizonte, v. 31, n. 1, p. 105-135, jan./abr. 2020 
Ensino da Disciplina de Contabilidade Geral em Cursos de Graduação em Administração: uma Análise Empírica da Relação entre a Satisfação e o Desempenho Discente

e a metodologia utilizadas para ministrar os conteúdos. A categoria "Envolvimento do estudante" capta o interesse, comportamento e satisfação dos alunos em relação à disciplina de Contabilidade. Já a categoria "Interação estudante/professor" avalia o ambiente e a relação do professor e dos alunos, no processo de ensino-aprendizagem. A vertente "Demandas da disciplina" trata da metodologia utilizada pelos professores para ministrar as disciplinas de Contabilidade e da satisfação dos discente sobre os materiais de apoio utilizado. Por fim, a categoria "Organização da disciplina" compreende a percepção dos discentes sobre a organização da disciplina, a disponibilidade do material e o atendimento das suas expectativas.

Como resultado, Beuren et al. (2013) notaram que as questões que apresentaram maior entropia foram: na categoria "envolvimento do professor", os exemplos utilizados pelo docente para fomento da compreensão do conteúdo e a apresentação do conteúdo de forma entusiasmada pelo professor; no "envolvimento do estudante" destacaram-se o interesse do aluno pelo conteúdo e sua percepção de tornar-se mais competente em sua área do estudo, a partir da disciplina de contabilidade introdutória; na "interação professor-estudante", questões que destacam a atitude do professor em encorajar o estudante a expressar sua opinião e se o professor é receptivo a novas ideias e diferentes pontos de vista advindos dos aluno; em relação às "demandas da disciplina" destaca as questões que tratam da apresentação do conteúdo da disciplina de contabilidade introdutória de forma rápida e o entendimento de que as leituras sugeridas são de difícil compreensão; por fim, na categoria "organização da disciplina", destaca-se a verificação do atendimento das expectativas dos alunos acerca da disciplina.

Por meio da aplicação de 586 questionários a discentes do $7^{\circ}$ ao $10^{\circ}$ período, em 3 Universidades Federais e 18 faculdades particulares nos Estados de Pernambuco, Paraíba, Rio Grande do Norte, Alagoas e Bahia, Crispim e Miranda (2013) concluíram que, nas instituições pesquisadas, com exceção da Universidade do Oeste de Santa Catarina (Unoesc), os docentes enfatizam o débito, crédito e razonete contábil, com pouca ou nenhuma ênfase nos aspectos gerenciais e decisório, que os relatórios gerados pela contabilidade podem oferecer. Borges e Mafra (2013) observaram que os alunos compreendem relativamente bem o que é ensinado na sala de aula nas disciplinas de Contabilidade, mas, no entanto, não se sentem suficientemente seguros diante das avaliações e da prática dentro das organizações.

Por fim, Alves, Teixeira e Oliveira (2017) constataram que os discentes consideram importante os conhecimentos contábeis para sua formação profissional e reconhecem a interdisciplinaridade da Administração, Contabilidade entre outras. Com suporte no explicitado acima, destaca-se que o proposto nesse estudo, relacionar "satisfação discente" ao "desempenho auto reportado", comporta-se como um diferencial, bem como uma complementação, ao conhecimento científico existente.

Assim, de uma forma geral, nota-se que os discentes, de variados cursos, têm consciência da relevância da disciplina de Contabilidade para suas formações, no entanto, existe insegurança no tocante à realização de atividades e práticas nas firmas. Esse resultado sinaliza pela importância dos docentes repensarem suas práticas pedagógicas, sobretudo na perspectiva de incrementar a ligação entre teoria e a prática. 


\subsection{Desenvolvimento das Hipóteses de Pesquisa}

A proposta do presente estudo é, então, propor que as dimensões "Envolvimento do professor", "Interesse do aluno", "Interação estudanteprofessor", "Demandas da disciplina" e "Organização da disciplina" são construtos de primeira ordem do construto mais abrangente (de segunda ordem) denominado "Satisfação Discente". Em outras palavras, argumenta-se que, no cenário de existir alto níveis de envolvimento docente e discente, alta Interação estudante-professor, demandas adequadas e boa organização da disciplina, por extensão, haverá melhor "Satisfação Discente". Válido destacar que, Beuren et al. (2013), apesar de validarem as 5 (cinco) dimensões para o contexto brasileiro com a utilização da técnica de Entropia Informacional, o estudo, em questão, avança com um diferencial, pois enseja validar as mesmas dimensões como construtos de primeira ordem que formam a "Satisfação Discente" (no caso, construto de segunda ordem). Sendo oportuno revelar, também que, a literatura empírica que validou o modelo proposto no contexto brasileiro via Modelagem de Equações Estruturais na vertente confirmatória - CB-SEM (por exemplo: Santos Neto, Dantas e Machado, 2017; Vieira, Milach e Huppes, 2008; Gomes, Dagostini e Cunha, 2013; e Cunha, Gomes e Beck, 2016), além de (com exceção de Santos Neto, Dantas e Machado, 2017) trabalharem com amostras relativamente restritas (224, 212 e 257 discentes, respectivamente), na avaliação da qualidade do ajuste do modelo de mensuração, muito embora seja reportados os índices de ajustamento da matriz teórica versus empírica do modelo, não há reporte das medidas de validade do construto - confiabilidade dos indicadores, validades convergente e discriminante e a confiabilidade composta.

Uma vez que esta abordagem adotada impossibilita a obtenção de medidas que assegurem a validade dos construtos, tal estratégia, no ponto de vista dos presentes autores, impossibilita, efetivamente, a validação (confirmação) da escala. Assim, na presente proposta, além de ser resolvido a controversa escolha de modelar um construto com apenas um item ("Satisfação Discente", a exemplo de Vieira, Milach e Huppes, 2008), propõe-se um modelo mais parcimonioso em decorrência da modelagem da "Satisfação Discente" como construto de segunda ordem. Ademais, o presente estudo avança, conforme apresentado anteriormente, ao avaliar o impacto da "Satisfação Discente" no desempenho, auto reportado pelo aluno, na disciplina de Contabilidade Geral.

Inicialmente, faz-se necessário conduzir o entendimento do construto de segunda ordem "Satisfação Discente" como toda percepção subjetiva referente a experiência educacional do discente, no caso, o estado psicológico associado a confirmação ou refutação das suas expectativas frente à realidade acadêmica vivenciada (Chen, \& Lo, 2012; Jaradeen, Jaradat, Safi, \& Tarawneh,.., 2012). Nesse aspecto, a "Satisfação Discente" pode ser fortemente relacionada com a qualidade do processo de ensino-aprendizagem dos discentes, como pelas características da instituição educacional, bem como pela percepção vinculada ao ambiente de ensino (Chen, \& Lo, 2012; Kantek, \& Kazanci, 2012; Astin, 1984). Ademais, pode vir a contemplar distintas medidas, tais como: relação teoria e prática; qualidade da instrução recebida e do curso; sistema de avaliação; relação interpessoal entre docentes e discentes; grade curricular; gestão da instituição educacional (infraestrutura e recursos) e dentre outras (Astin, 1984; Lee, White, \& Hong, 2009). Dito isso, a "Sastifação Discente" está 
Ensino da Disciplina de Contabilidade Geral em Cursos de Graduação em Administração: uma Análise Empírica da Relação entre a Satisfação e o Desempenho Discente

diretamente relacionada ao atendimento de expectativas discentes, estando, essas, alinhadas aos construtos de primeira ordem do estudo.

O primeiro construto, "Interação Estudante-Professor", relaciona-se à qualidade da relação entre ambos (discente/docente), materializando-se em espaço/abertura para argumentações, questionamentos, discussões e esclarecimentos de dúvidas relativas ao conteúdo ministrado, sendo notada uma ampla liberdade de expressão dos diversos pontos de vista por parte do discente (Paswan, \& Young, 2002). Assim, a manutenção de um clima favorável de sala de aula, dada por essa interação, desempenha um papel significativo na aprendizagem discente e, por conseguinte, na qualidade do ensino (Fraser, Aldridge, \& Soerjaningsih, 2010). Para tanto, os docentes devem demonstrar boas qualidades de liderança, serem mais amigáveis, ajudar e prestar mais atenção às necessidades dos discentes com o intuito de proporcionar maior satisfação por parte desses (Chen, 2017). Nesse ponto, formula-se a primeira hipótese de pesquisa:

$H_{1}$ - A "Interação estudante-professor" impacta direta e positivamente a "Satisfação Discente".

"Demandas da disciplina", segundo construto, relaciona-se à forma como o docente ministra o conteúdo da disciplina, logo, compreende a intensidade com que são trabalhadas atividades em sala ou extraclasse, leituras de livros e materiais suplementares (Paswan, \& Young, 2002), portanto, argumenta-se que a forma como o docente ensina conteúdo, desenvolve as atividades e trabalha em sala de aula pode influenciar negativamente ou positivamente na avaliação da disciplina e até do próprio docente (Santos Neto, Dantas, \& Machado, 2017; Paswan, \& Young, 2002; Vieira, Milach, \& Huppes, 2008). Por certo, evidencia-se que, se os docentes puderem desenvolver as atividades e trabalhar em sala de aula de maneira satisfatória, maior será o interesse do aprender discente para com o conteúdo ministrado (Santos Neto, Dantas, \& Machado, 2017), ensejando, por tabela, em indícios de satisfação discente (Navarro, Iglesias, \& Torres, 2005), haja vista se construirá um ambiente propício ao ensino-aprendizagem. Diante do exposto, formula-se a segunda hipótese de pesquisa:

$\mathrm{H}_{2}$ - As "Demandas da disciplina" impactam direta e positivamente na "Satisfação Discente".

No terceiro construto "Organização da disciplina", a explanação do docente em sala de aula, bem como uma apresentação sequenciada de forma sistematizada e adequada do conteúdo programático, facilitando a absorção dos assuntos abordados, bem como a acessibilidade e disponibilidade do material bibliográfico a ser utilizado, corroboraram no pleno atendimento das expectativas esperadas pelos discentes (Paswan, \& Young, 2002).

Em suma, disciplinas/cursos mais organizados e estruturados levam 0 discente a uma avaliação mais favorável do conteúdo ministrado pelo docente (Paswan, \& Young, 2002), sendo elemento chave para alcance da satisfação discente (Navarro, Iglesias, \& Torres, 2005). Dessa forma, a satisfação discente será, em tese, evidenciada, posto estado psicológico de confirmação das suas expectativas (Chen, \& Lo, 2012; Jaradeen et al., 2012), em vistas do pleno entendimento explícito de "como" a disciplina ministrada será conduzida no 
processo de aprendizagem dos discentes envolvidos. Diante do exposto, formulase a terceira hipótese de pesquisa:

$\mathrm{H}_{3}$ - A "Organização da disciplina" impacta direta e positivamente a "Satisfação Discente".

O "Envolvimento do Professor", quarto construto do estudo, destaca-se pelo comportamento docente de forma adequada, com entusiasmo, domínio e efetivo interesse, fazendo jus a utilização de uma metodologia coerente para ministrar seus conteúdos (Cashin, 1995; Paswan, \& Young, 2002). Dito isso, a demonstração de entusiasmo e coragem para ensinar é essencial para estabelecer um vínculo entre ambos, assim, o discente perceberá o docente como alguém capaz de ajudar a entender a disciplina e não um tirano que pretende reprová-lo e, na sequência, a motivação para o aprender (Santos Neto, Dantas, \& Machado, 2017).

Corroborando nessa lógica, Naimie, Siraj, Abuzaid e Shagholi . (2010) argumentam acerca da importância dos docentes construírem atividades que otimizem os resultados de aprendizagem, bem como enfatiza o pleno entendimento das reivindicações e preferências dos discentes como forma de consubstanciar suas conquistas acadêmicas. E, uma vez que o discente tendo suas expectativas atendidas, evidencia-se reflexos positivos na sua satisfação (Santos Neto, Dantas, \& Machado, 2017), logo, diante do exposto, formula-se a quarta hipótese de pesquisa:

$\mathrm{H}_{4}-\mathrm{O}$ "Envolvimento do professor" impacta direta e positivamente a "Satisfação Discente".

No quinto construto do estudo, "Interesse do aluno", relaciona-se com o nível de atenção e interesse que é dado as aulas, bem como sua percepção acerca da sua evolução intelectual ao longo do curso/disciplina, no caso, desenvolvimento do seu perfil competente (Vieira, Milach, \& Huppes, 2008). Dessa forma, a percepção oriunda da trajetória acadêmica, voltada para oportunidades no desenvolvimento da carreira, enseja peso relevante na satisfação discente, já que favorece condições ao ingresso no mundo do trabalho e para a vida profissional (Ramos, Barlem, Lunardi, Barlem, Silveira, \& Bordignon, 2015; SOUZA; REINERT, 2010).

Nesse sentido, compreender de fato o "interesse do aluno" e identificar seus fatores geradores são prerrogativas para alcance da satisfação das suas necessidades (RAMOS et al. 2015). Nessa perspectiva, formula-se a quinta hipótese de pesquisa:

$\mathrm{H}_{5}$ - O "Interesse do aluno" impacta direta e positivamente a "Satisfação Discente".

No tangente a construção da última hipótese do estudo, tem-se que dado aos divergentes relacionamentos identificados na literatura entre satisfação discente e a nota atribuída ao seu aprendizado, advoga-se na contínua pesquisa sobre o entendimento dessa relação (Abbasi, Malik, Chaudhry, \& Imdadullah,, 2011). Para tanto, norteiam-se por observações de relacionamento moderado (Liu, \& Jung, 1980; Pike, 1991), sem significância (Bean, \& Bradley, 1986) e significativas (Sockalingam, 2012; Centra, \& Rock, 1971; Ko, \& Chung, 2014). No entanto, opta-se pelo discurso de que alunos satisfeitos tendem a apresentarem maior nível de aprendizado, que se materializa na compreensão dos conteúdos 
Ensino da Disciplina de Contabilidade Geral em Cursos de Graduação em Administração: uma Análise Empírica da Relação entre a Satisfação e o Desempenho Discente

ministrados (Neves Júnior, \& Rocha, 2010; Santos et al., 2011) e, consequentemente, em maior desempenho acadêmico (Sockalingam, 2012; Ko, \& Chung, 2014), daí, formula-se a sexta hipótese de pesquisa:

$\mathrm{H}_{6}$ - A "Satisfação Discente" impacta direta e positivamente no "Rendimento Acadêmico".

Na Figura 1, reporta-se o modelo estrutural proposto. Além dos 5 (cinco) construtos de "primeira ordem" que formam o "construto de segunda ordem" "Satisfação Discente", e do "construto endógeno alvo" "Rendimento Acadêmico", tem-se o reporte das 4 (quatro) variáveis de controle inseridas no modelo: Gênero; Idade; Período; e Instituição de Ensino.

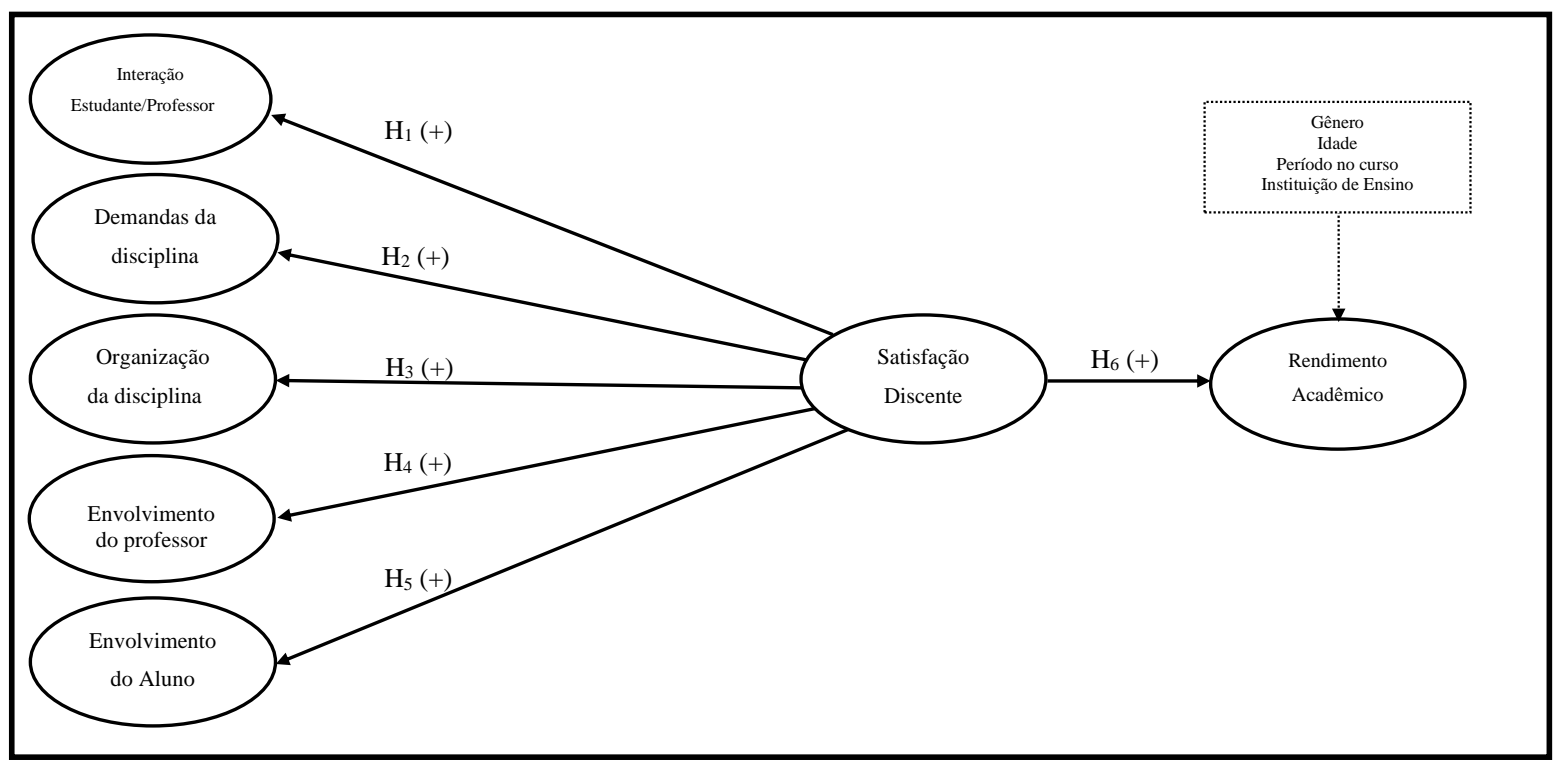

Figura 1 - Modelo estrutural e hipóteses formuladas.

Nota: o símbolo (+) representa relações positivas, enquanto que o símbolo (-) indica relações negativas

Fonte: Elaboração própria.

Conforme pode ser observado na Figura 1, o modelo proposto apresenta setas contínuas representando os relacionamentos de impacto direto, sendo reportados apenas símbolos positivos "(+)" para sinalizar a previsão de existência de relações positivas nos relacionamentos. Assim, a "Satisfação discente" foi modelada como um "construto de segunda ordem" formado, reflexivamente, pelos os 5 (cinco) construtos compreendidos no estudo de Paswan e Young (2002) e adaptados ao contexto brasileiro por Beuren et al. (2013). No entanto, além da satisfação discente ser proposta como um construto de segunda ordem, o modelo estrutural proposto inova ao incorporar o rendimento acadêmico discente como variável endógena alvo (construto independente), sendo, esta, uma importante contribuição à literatura empírica.

Por fim, uma vez que o objetivo é investigar os relacionamentos entre os construtos livre da influência de outras variáveis (Hair Jr., Black, Babin, Anderson, \& Tatham, 2014), foram inseridas no modelo estrutural proposto (dentro do retângulo no canto superior da Figura 1), 4 (quatro) variáveis de controle, a saber: 
"Gênero", "Idade", "Período no curso"; e "Tipo de Instituição de Ensino" (pública ou privada).

\section{METODOLOGIA DA PESQUISA}

A investigação foi operacionalizada via survey, através de questionário estruturado em escala do tipo Likert, de cinco pontos (no caso, 1 = Discordo Totalmente e 5 = Concordo Totalmente). Quanto ao universo da pesquisa, foram compreendidas 7 (sete) Instituições de Ensino Superior das cidades de Floriano-PI, Teresina-PI, Picos-PI e Parnaíba-Pl, que ofertam o curso de graduação em Administração, presencialmente, sendo contempladas: 3 (três) universidades públicas federais; 1 (uma) universidade pública estadual; e 3 (três) faculdades privadas, na qual o critério de escolha da amostra foi a acessibilidade. Como instrumento de coleta de dados, foi utilizado um questionário composto por dois blocos. Inicialmente, buscou-se coletar informações descritivas, enquanto que o segundo bloco, desenvolvido alinhado ao instrumento desenvolvido por Paswan e Young (2002), validado ao contexto brasileiro por Beuren et al. (2013), possibilitou investigar a satisfação discente nos 5 (cinco) seguintes constructos: "Envolvimento do professor"; "Interesse do aluno"; "Interação professor/aluno"; "Demandas da disciplina" e "Organização da disciplina". Adicionalmente, trabalhou-se um item específico para capturar o desempenho, auto reportado, obtido pelos discentes na disciplina de Contabilidade Geral. Ao todo, é composto por 30 (trinta) questões, com 6 (seis) itens cada construto.

Para uma melhor adequação do instrumento utilizado na coleta dos dados foi realizado um pré-teste em uma turma do $7^{\circ}$ (sétimo) período com uma amostra de 26 (vinte e seis) graduandos em Administração. Esse procedimento permitiu avaliar preliminarmente a consistência internas dos itens (via Alpha de Crombach), possibilitando, assim, a realização de eventuais ajustes (de tradução) para melhor compreensão do questionário, reduzindo, assim, o risco de enviesamento dos dados.

Diante disso, foram impressos e aplicados em sala de aula para os graduandos de Administração que, no $1^{\circ}$ (primeiro) semestre de 2018, estavam cursando entre $\circ 3^{\circ}$ (terceiro) e o $8^{\circ}$ (oitavo) períodos das 7 (sete) instituições de ensino pesquisadas. A nota foi obtida por meio da média final, auto reportada, obtida na disciplina, podendo ser; aprovado por média ou por exame final. Obteve-se no total uma amostra de 528 (quinhentos e vinte e oito) acadêmicos de administração de empresas, de ambos os gêneros, que estavam cursando ou já tinham cursado a disciplina de Contabilidade Geral (ou correlata em nome e na ementa, obrigatoriamente).

Na Figura 2, reporta-se os itens, seus respectivos construtos: 


\begin{tabular}{|c|c|}
\hline Categoria & Atributos \\
\hline \multirow{6}{*}{$\begin{array}{l}\text { Envolvimento } \\
\text { do professor }\end{array}$} & $\begin{array}{l}\text { EP1) O professor apresenta o conteúdo de forma } \\
\text { entusiasmada. }\end{array}$ \\
\hline & EP2) Ao ensinar, o professor parece interessado. \\
\hline & $\begin{array}{l}\text { EP3) Os exemplos utilizados pelo professor ajudam na } \\
\text { compreensão do conteúdo. }\end{array}$ \\
\hline & $\begin{array}{l}\text { EP4) O professor procura saber se o estudante aprendeu } 0 \\
\text { conteúdo. }\end{array}$ \\
\hline & $\begin{array}{l}\text { EP5) O professor procura relacionar a teoria e a prática } \\
\text { profissional. }\end{array}$ \\
\hline & $\begin{array}{l}\text { EP6) A titulação do professor é adequada para ministrar a } \\
\text { disciplina. }\end{array}$ \\
\hline \multirow{6}{*}{$\begin{array}{l}\text { Envolvimento } \\
\text { do estudante }\end{array}$} & $\begin{array}{l}\text { EE1) Você se sente interessado em aprender o conteúdo da } \\
\text { disciplina. }\end{array}$ \\
\hline & EE2) Geralmente você fica atento em sala de aula. \\
\hline & EE3) Você sente que a disciplina lhe desafia intelectualmente. \\
\hline & $\begin{array}{l}\text { EE4) Você acredita estar mais competente na sua área de } \\
\text { estudo. }\end{array}$ \\
\hline & $\begin{array}{l}\text { EE5) Geralmente você participa de discussões em sala de } \\
\text { aula. }\end{array}$ \\
\hline & EE6) É positivo o meu desempenho ao longo da disciplina \\
\hline \multirow{5}{*}{$\begin{array}{l}\text { Interação } \\
\text { estudante/professor }\end{array}$} & $\begin{array}{l}\text { IEP1) O professor encoraja o estudante a expressar sua } \\
\text { opinião. }\end{array}$ \\
\hline & $\begin{array}{l}\text { IEP2) O professor é receptivo a novas ideias e diferentes pontos } \\
\text { de vista. }\end{array}$ \\
\hline & $\begin{array}{l}\text { IEP3) Os estudantes têm oportunidade para fazerem } \\
\text { perguntas. }\end{array}$ \\
\hline & $\begin{array}{l}\text { IEP4) O professor geralmente estimula a discussão em sala de } \\
\text { aula. }\end{array}$ \\
\hline & $\begin{array}{l}\text { IEP5) O professor disponibiliza aos seus alunos materiais de } \\
\text { estudo sobre as aulas dadas. } \\
\text { IEP6) É permitido aos alunos contatar os professores fora do } \\
\text { ambiente da sala de aula. }\end{array}$ \\
\hline \multirow{6}{*}{$\begin{array}{l}\text { Demandas } \\
\text { disciplina }\end{array}$} & $\begin{array}{l}\text { DD1) O professor aborda muitos conteúdos (além do } \\
\text { necessário). }\end{array}$ \\
\hline & DD2) O professor apresenta o conteúdo muito rapidamente. \\
\hline & $\begin{array}{l}\text { DD3) Os trabalhos realizados consomem muito tempo em } \\
\text { relação ao conhecimento que agregam. }\end{array}$ \\
\hline & DD4) Você acha as leituras indicadas muito difíceis. \\
\hline & $\begin{array}{l}\text { DD5) Os materiais utilizados pelo professor são de boa } \\
\text { qualidade. }\end{array}$ \\
\hline & $\begin{array}{l}\text { DD6) O professor trabalha todos conteúdos previstos na } \\
\text { ementa da disciplina. }\end{array}$ \\
\hline \multirow{6}{*}{ Organização da disciplina } & $\begin{array}{l}\text { OD1) O professor relaciona os conteúdos de forma } \\
\text { sistemática. }\end{array}$ \\
\hline & OD2) A disciplina é bem organizada. \\
\hline & $\begin{array}{l}\text { OD3) É fácil fazer anotações das apresentações realizadas } \\
\text { pelo professor. }\end{array}$ \\
\hline & $\begin{array}{l}\text { OD4) A sequência do conteúdo da disciplina é apresentada } \\
\text { de maneira adequada. }\end{array}$ \\
\hline & $\begin{array}{l}\text { OD5) A disponibilização do material da disciplina é de fácil } \\
\text { acessibilidade (meio físico ou virtual) }\end{array}$ \\
\hline & $\begin{array}{l}\text { OD6) De uma maneira geral a disciplina atende as minhas } \\
\text { expectativas. }\end{array}$ \\
\hline
\end{tabular}

Figura 2 - Definição constitutiva dos construtos contemplados na pesquisa Fonte: Beuren et al. (2013). 
Uma vez que o objetivo do presente estudo foi relacionar a satisfação discente ao desempenho (ao reportado) obtido na disciplina, de forma exploratória, optou-se, como técnica de análise dos dados, pela técnica multivariada de Modelagem de Equações Estruturais na abordagem de Mínimos Quadrados Parciais (Partial least squares structural equation modeling - PLS-SEM), utilizando, para tal, o software SmartPLS® V. 2.0.

A opção pela técnica PLS-SEM se justifica pela proposta exploratória de modelar a "Satisfação Discente" como construto de segunda ordem, além de ser incorporado ao modelo estrutural, como variável independente alvo, o desempenho, auto reportado pelo aluno, na disciplina de Contabilidade Geral, algo, no conhecimento dos autores, não investigado pela literatura empírica nacional.

\section{ANÁLISE DOS DADOS}

\subsection{Caracterização da Amostra}

Conforme apresentado anteriormente, foram compreendidos no estudo 528 discentes do curso de Administração, sendo 368 vinculados às 4 (quatro) universidades públicas e 160 às 3 (três) instituições de ensino superior privadas. $O$ critério adotado para participação no presente estudo foi estar cursando, no mínimo, o $3^{\circ}$ (terceiro) período (período no qual, em tese, os alunos já pagaram pelo menos uma disciplina de Contabilidade), assim, foi obtida a seguinte distribuição: 50 discentes do $3^{\circ}$ período; 80 discentes do $4^{\circ}$ período; 137 discentes do $5^{\circ}$ período; 106 discentes do $6^{\circ}$ período; 59 discentes do $7^{\circ}$ período; e 57 discentes do $8^{\circ}$ período. Ressalta-se que, 39 discentes $(7,4 \%)$ não reportaram o perío do que cursavam atualmente. Cerca de $45 \%$ da amostra (235 respondentes) se auto declararam do gênero feminino, enquanto $49 \%$ (257 alunos) indicaram pertencer ao gênero masculino, sendo que pouco mais de $6 \%$ da amostra (36 discentes) não reportaram o gênero. Relativo à idade, foi notada uma média de 22,34, com desvio padrão de 4,87 anos, indicando, assim, uma predominância de jovens respondentes. A idade máxima foi de 50 anos, enquanto que a mínima foi de 18 anos. Por fim, acerca da nota média final auto reportada, a média final de 8,28, com desvio padrão de 1,21 , possibilita concluir pela existência de rendimento (auto reportado) mediano/elevado na amostra estudada, sendo notado o reporte de 0 (zero) como nota mínima e 10 (dez) como nota máxima obtida. Concluída essa breve caracterização descritiva da amostra estudada, a seguir são apresentadas as estatísticas descritivas de cada construto investigado.

\subsection{Estatística Descritiva das Variáveis}

A fim descrever, sistematizar e avaliar as relações entre as variáveis das escalas estudadas, realizou-se a análise estatística descritiva. O construto "Envolvimento do professor" apresenta indicadores com médias mais próximas do teto 5 e menores níveis de discordância (desvio padrões), sendo notado que o item "EP6" ("A titulação do professor é adequada para ministrar a disciplina") é, na percepção dos respondentes, àquele mais relevante, uma vez que 
Ensino da Disciplina de Contabilidade Geral em Cursos de Graduação em Administração: uma Análise Empírica da Relação entre a Satisfação e o Desempenho Discente

apresentou maior média $(4,1783)$ e menor desvio padrão $(0,85316)$. Por outro lado, são notadas pontuações de concordância mais baixas nos itens "EP4" ("O professor procura saber se o estudante aprendeu o conteúdo") (Média=3,7725) e "EP5" ("O professor procura relacionar a teoria e a prática profissional") (média $=3,7739$ ).

Com exceção da variável "EP5" (que apresentou valor de -0,27), todas as demais variáveis reportaram valores positivo para Curtose, indicando, assim, a existência de distribuição Leptocúrtica, isto é, com observações concentradas em torno da média. Relativo à assimetria, todas as variáveis apresentaram valores negativos (assimétrica negativa ou à esquerda), sinalizando que a maior parte das respostas mostram-se superior à média. Assim, no seu conjunto, as estatísticas descritivas indicam que, muito embora seja importante incrementar a ligação entre teoria à prática no âmbito da prática pedagógica, na percepção dos discentes investigados, existe um nível importante de satisfação no âmbito do construto "Envolvimento do professor".

O constructo "Envolvimento do estudante" também apresentou indicadores com médias elevadas (próximas a 5) e baixos níveis de discordância (desvio padrões), tendo o item "EE l" ("Você se sente interessado em aprender o conteúdo da disciplina") se mostrado o mais relevante na percepção dos discentes, uma vez que apresentou maior média $(4,1027)$ e menor desvio padrão $(0,93270)$ nessa escala. Em contrapartida a variável "EE5" ("Geralmente você participa de discursões em sala de aula") apresentou menor média $(3,4668)$ e maior desvio padrão (1,03191), sinalizando que, na percepção da amostra, os alunos se interessam em aprender os conteúdos ministrados, mas em geral, não costumam participam ativamente das discussões dos temas da disciplina na sala de aula. Exceto pela variável "EE5" (valor de -0,45), as variáveis apresentaram valores positivo para curtose, logo, tem-se, novamente, uma concentração de observações concentradas em torno da média.

Os valores negativos para assimetria permitem concluir, mais uma vez, que a maior parte das respostas são superiores à média. Logo, a exemplo do construto "Envolvimento do professor", conclui-se, preliminarmente, pela existência, na percepção discente, de nível importante de satisfação no âmbito do construto "Envolvimento do estudante". No constructo "Interação aluno/professor", notase que, mais uma vez, de uma forma geral, as médias atribuídas são relativamente elevadas com um baixo nível de discordância. A variável mais relevante, na percepção dos alunos, foi "IEP3" ("Os estudantes têm oportunidade para fazerem perguntas) com média de 4,4297, desvio padrão de 0,68169, curtose de 1,45 e assimetria de $-1,11$.

No outro extremo, os itens com piores desempenhos foram "IEP1" ("O professor encoraja seus estudantes a expressarem sua opinião") (média de 3,7581; desvio de 0,99; curtose de -0,16; e assimetria de -0,54) e "IEP4" ("O professor geralmente estimula a discursão em sala de aula") (média de 3,8693; desvio de 0,95; curtose de -0,24; e assimetria de -0,55). Logo, na percepção dos alunos, embora sejam dadas oportunidades para questionamentos durante a aula, na percepção de parte dos alunos, há necessidade de maior estímulo, por parte do professor, para que o aluno expresse sua opinião e promova/participe dos debates em sala de aula (resultado sinalizado pela assimetria negativa observações relativamente dispersas em torno da média). 
Esse último resultado, combinado com o desempenho apresentado na variável "EE5" ("Geralmente você participa de discussões em sala de aula") do constructo "Envolvimento do estudante", pode sugerir que os docentes de Contabilidade, na amostra analisada, sistematicamente têm inibido a participação ativo dos discentes, ocasionando, assim, entre outros fatores, no baixo desenvolvimento da visão crítica e da capacidade de interpretação por parte dos mesmos (JÚNIOR; ROCHA, 2010), sendo, nesse ponto, necessária a adoção de mecanismos/iniciativas de fomento à participação discente em sala de aula. No entanto, ressalta-se que mais estudos nesse aspecto específico se fazem necessários.

O constructo "Demandas da Disciplina" foi o que apresentou as menores médias, maior variabilidade (desvio padrão), dispersão dos resultados em torno da média (curtose negativa) e concentração de respostas inferiores à média (assimetria positiva). Especial destaque ocorre nos itens "DD4" ("Você acha as leituras indicadas muito difícil") com média de 2,7414, desvio padrão de 1,11236, curtose de $-0,5227$ e assimetria de 0,2933, "DD3" ("Os trabalhos realizados consomem muito tempo em relação ao conhecimento que agrega") com média de 2,8145, desvio padrão de 1,05899, curtose de $-0,5956$ e assimetria de 0,002) e "DD2" ("O professor apresenta o conteúdo muito rapidamente") com média de 2,9015, desvio padrão de 1,10027, curtose de -0,6491 e assimetria de 0,008.

Os resultados desses três itens, no seu conjunto, permitem concluir que, na percepção dos discentes participantes da pesquisa, inexiste insatisfação, haja vista $\mathrm{o}$ entendimento de que o docente não propõe leituras difíceis, não apresenta o conteúdo das as aulas com pressa e propõe trabalhos que geram conhecimento. No último constructo, "Organização da Disciplina", também foram notados indicadores com maiores médias e menores níveis de discordância, tendo o item "OD5" ("A disponibilização do material da disciplina é de fácil acessibilidade (meio físico ou virtual"), com média de 4,0266 e desvio padrão de 0,92982 , se destacado positivamente. Em contrapartida a variável que obteve menor média foi "OD6" ("De uma maneira geral a disciplina atende as minhas expectativas") (3,7841), com desvio padrão de 1,07179.

Assim, uma vez que todos os construtos apresentaram valores positivos para curtose e negativos para assimetria, é notada uma concentração de repostas superiores às médias, conclui-se que, na percepção dos discentes investigados, os conteúdos ministrados nas disciplinas de contabilidade, muitas vezes, atendem as suas expectativas, existindo, nesse aspecto, pouco distanciamento entre o que é ensinado e o que, de fato, eles desejam aprender.

Assim, no geral, pode-se notar que, as médias evidenciadas dos itens de cada construto do estudo sinalizam pelo direcionamento de uma boa conduta de ensino-aprendizagem, que em tese, pode-se refletir em indícios de satisfação por parte dos discentes investigados no presente estudo. Concluída essas análises descritivas preliminares da caracterização da amostra e das respostas apresentadas pelos discentes investigados, a seguir é reportada os resultados da análise multivariada. 
Ensino da Disciplina de Contabilidade Geral em Cursos de Graduação em Administração: uma Análise Empírica da Relação entre a Satisfação e o Desempenho Discente

\subsection{Avaliação do Modelo de Mensuração}

Alinhado a Nascimento e Macedo (2016), dado a necessidade de se avaliar a unidimensionalidade de cada escala utilizada, foi utilizada a Análise Fatorial Exploratória (AFE), com o método de Componentes Principais, com a utilização de rotações oblíquas (oblimin diretc), uma vez que "era esperada a existência de correlação entre os construtos" (Nascimento, \& Macedo, 2016, p. 299).

Em termos de resultados, foi observado que os construtos: "Envolvimento do professor" (Kaiser-Meyer-Olkin - KMO de 0,868, com valor de 1,502,47, significante a 0,000 no teste de esfericidade de Bartlett, comunalidade média de 0,618, variância explicada de 61,76 com extração de um fator, Alfa de Cronbach de 0,874 e correlações médias de 0,539, significantes a 0,01); "Envolvimento do estudante" (KMO 0,807, valor de 691,42 significante a 0,000 no teste de esfericidade de Bartlett, comunalidade média de 0,47, variância explicada de 47,02 com extração de um fator, Alfa de Cronbach de 0,762 e correlações médias de 0,37 significantes a 0,01); "Interação Estudante/Professor" (KMO 0,838, com valor de 1.015,92 significante a 0,000 no teste de esfericidade de Bartlett, comunalidade média de 0,52, variância explicada de 52,23 com extração de um fator, Alfa de Cronbach de 0,822 e correlações médias de 0,42 significantes a 0,01 ); "Demandas da disciplina" (KMO 0,676, com valor de 267,45 significante a 0,000 no teste de esfericidade de Bartlett, comunalidade média de 0,482, variância explicada de 47,81 com extração de um fator, Alfa de Cronbach de 0,68 e correlações médias de 0,33 significantes a 0,01) e "Organização da disciplina" (KMO 0,889, com valor de 1.549,83 significante a 0,000 no teste de esfericidade de Bartlett, comunalidade média de 0,628, variância explicada de 62,82 com extração de um fator, Alfa de Cronbach de 0,879 e correlações médias de 0,55 significantes a 0,01) apresentaram indícios que permitiram concluir pela existência da unidimensionalidade.

Uma vez que todos os construtos foram capturados por meio de escalas de mensuração reflexiva, o Modelo de Mensuração foi avaliado através da análise da: confiabilidade composta (composite reliability); validade convergente (variance extracted); confiabilidade do indicador (indicator reliability); e validade discriminante (discriminant validity). Inicialmente, o modelo de mensuração foi testado com todas os 30 itens (cada escala foi mensurada com 6 itens, alinhado a Beuren et al. (2013), no entanto, alguns itens apresentaram níveis insuficiente de confiabilidade (coeficientes padronizados com cargas externas bem inferiores a $0,708$ ) acarretando em baixa validade convergente (AVE $>0,5)$ e inexistência de validade discriminante (correlações entre os construtos superiores à raiz quadrada das respectivas AVE's dos construtos) (Nascimento, \& Macedo, 2016). Assim, foram removidas as variáveis que não atendiam os critérios propostos por Hair Jr. et al. (2009), isto é: valores p associados inferiores a 0,05; e cargas com valor igual ou superior a 0,5, bem como níveis inaceitáveis de validade convergente (AVE>0,5).

O resultado final é reportado, na Tabela 1: 
Tabela 1

Avaliação do modelo de mensuração

\begin{tabular}{|c|c|c|c|c|c|}
\hline $\begin{array}{l}\text { Cargas Fatoriais } \\
\text { Padronizadas }\end{array}$ & \begin{tabular}{|c|} 
Demandas \\
da \\
disciplina \\
\end{tabular} & $\begin{array}{l}\text { Envolvimento } \\
\text { do professor }\end{array}$ & $\begin{array}{c}\text { Interação } \\
\text { estudante/professor }\end{array}$ & $\begin{array}{l}\text { Organização } \\
\text { da disciplina }\end{array}$ & \begin{tabular}{|c}
$\begin{array}{c}\text { Envolvimento } \\
\text { do } \\
\text { estudante }\end{array}$ \\
\end{tabular} \\
\hline DemDisp2 & 0,781 & & & & \\
\hline DemDisp3 & 0,656 & & & & \\
\hline DemDisp4 & 0,405 & & & & \\
\hline EnvProfl & & 0,637 & & & \\
\hline EnvProf2 & & 0,714 & & & \\
\hline EnvProf3 & & 0,636 & & & \\
\hline EnvProf4 & & 0,639 & & & \\
\hline EnvProf5 & & 0,591 & & & \\
\hline EnvProf6 & & 0,487 & & & \\
\hline IntEstProfl & & & 0,665 & & \\
\hline IntEstProf2 & & & 0,653 & & \\
\hline IntEstProf3 & & & 0,547 & & \\
\hline IntEstProf4 & & & 0,677 & & \\
\hline IntEstProf5 & & & 0,427 & & \\
\hline OrgDiscl & & & & 0,711 & \\
\hline OrgDisc2 & & & & 0,727 & \\
\hline OrgDisc3 & & & & 0,544 & \\
\hline OrgDisc4 & & & & 0,692 & \\
\hline OrgDisc5 & & & & 0,426 & \\
\hline OrgDisc6 & & & & 0,668 & \\
\hline EnvEstl & & & & & 0,578 \\
\hline EnvEst2 & & & & & 0,427 \\
\hline EnvEst3 & & & & & 0,477 \\
\hline EnvEst4 & & & & & 0,608 \\
\hline EnvEst6 & & & & & 0,476 \\
\hline $\begin{array}{l}\text { Variância Média } \\
\text { Extraída (AVE) }\end{array}$ & 0,571 & 0,618 & 0,594 & 0,628 & 0,513 \\
\hline $\begin{array}{l}\text { Confiabilidade } \\
\text { Composta }\end{array}$ & 0,794 & 0,906 & 0,879 & 0,910 & 0,840 \\
\hline $\begin{array}{l}\text { Critério de Fornell- } \\
\text { Larcker* }\end{array}$ & \begin{tabular}{|l|} 
Demandas \\
da \\
disciplina \\
\end{tabular} & $\begin{array}{l}\text { Envolvimento } \\
\text { do professor }\end{array}$ & $\begin{array}{l}\text { Interação } \\
\text { estudante/professor }\end{array}$ & $\begin{array}{l}\text { Organização } \\
\text { da disciplina }\end{array}$ & $\begin{array}{l}\text { Envolvimento } \\
\text { do estudante }\end{array}$ \\
\hline $\begin{array}{ll}\begin{array}{l}\text { Demandas } \\
\text { disciplina }\end{array} & \text { da } \\
\end{array}$ & 0,756 & $-0,152$ & $-0,297$ & $-0,261$ & $-0,310$ \\
\hline $\begin{array}{l}\text { Envolvimento } \\
\text { do professor }\end{array}$ & $-0,152$ & 0,786 & 0,565 & 0,513 & 0,553 \\
\hline $\begin{array}{l}\text { Interação } \\
\text { estudante/professor }\end{array}$ & $-0,297$ & 0,565 & 0,771 & 0,759 & 0,700 \\
\hline $\begin{array}{ll}\text { Organização } & \text { da } \\
\text { disciplina } & \end{array}$ & $-0,261$ & 0,513 & 0,759 & 0,792 & 0,692 \\
\hline $\begin{array}{l}\text { Envolvimento } \\
\text { do estudante }\end{array}$ & $-0,310$ & 0,553 & 0,700 & 0,692 & 0,717 \\
\hline
\end{tabular}

Fonte: Dados da pesquisa

*Nota: Na diagonal principal são reportadas as Variância Médias Extraídas (AVEs) e, fora da diagonal, são apresentados os valores das correlações entre os constructos do modelo elevados ao quadrado

Conforme os resultados reportados na Tabela 1, analisando a confiabilidade dos indicadores (indicator reliability) através dos valores 
Ensino da Disciplina de Contabilidade Geral em Cursos de Graduação em Administração: uma Análise Empírica da Relação entre a Satisfação e o Desempenho Discente

reportados para as cargas fatoriais padronizadas, diante da significância de todos os coeficientes significantes ao nível de 0,01 e, sobretudo, da avaliação da existência de cargas fatoriais padronizadas superiores ao piso de 0,5 (sendo que o valor ideal para a carga fatorial padronizada é igual ou maior que 0,70 ), notouse a existência de itens com adequados níveis de confiabilidade. Ressalta-se que os itens DemDisp4, EnvProf5, EnvProf6, IntEstProf3, IntEstProf5, OrgDisc5, EnvEst2, EnvEst3, EnvEst6 apresentaram carga suficientemente próximas a 0,50, no entanto, ponderando que os demais indicadores de ajustamento já se mostravam adequados, optou-se por permanecer com estes os itens e excluir, apenas, àqueles que reportaram valores muito abaixo do piso estabelecido na literatura (DemDisp 1, DemDisp5, DemDisp6, IntEstProf6 e EnvEst5).

Seguindo à análise da Tabela 1, avalia-se a validade convergente de cada construto. "A validade convergente é a extensão em que uma medida se correlaciona positivamente com medidas alternativas do mesmo construto" (Nascimento, \& Macedo, 2016, p. 294). Uma vez que todos os cinco construtos apresentaram indicadores da Variância Media Extraída (AVE) superiores a 0,5, pode-se concluir pela existência de nível suficiente de validade convergente destes.

Acerca da confiabilidade composta, os valores reportados para cada construto (Demanda da Disciplina= 0,794; Envolvimento do Professor $=0,906$; Envolvimento Estudante/Professor = 0,879; Organização da Disciplina=0,910 e Envolvimento do Estudante $=0,840$ ) mostraram-se significativamente superiores ao piso de 0,70 estabelecido pela literatura, demostrando, assim, pela existência de confiabilidade composta por parte dos construtos investigados.

Por fim, no tocante à avaliação da validade discriminante - "a medida que um construto é verdadeiramente distinto dos demais por padrões empíricos" (Nascimento, \& Macedo, 2016, p. 294), utilizando o Critério de Fornell-Larcker, uma vez que todos os construtos apresentaram valores das AVEs superiores aos coeficientes de correlação frente aos demais constructos da escala, conclui-se pela existência de nível suficiente de validade discriminante.

Pode-se perceber, conforme reportado na Tabela 1, que o construto 'Demandas da disciplina' (com 3 itens, isto é, 'DemDisp2', 'DemDisp3' e 'DemDisp4') foi àquele que mais perdeu itens, no entanto, dado o caráter exploratório do presente estudo e uma vez que os valores reportados para a confiabilidade dos indicadores, validade convergente, validade discriminante e de confiabilidade composta, entende-se que a quantidade remanescente de itens para cada construto não impossibilitou o alcance dos objetivos delineados no presente estudo. A seguir, é reportada a análise dos relacionamentos entre os construtos investigados (Modelo Estrutural).

\subsection{Avaliação do Modelo Estrutural}

Concluída a etapa inicial de avaliação do modelo de mensuração, seguiuse para a investigação das relações estruturais. A Figura 3 demonstra os parâmetros estimados no modelo de equações estruturais. Conforme os resultados reportados na Figura 3, nota-se que, com exceção de "Demandas da disciplina" ( $\beta=-0,060 ; p<$ não significante), todos os demais construtos de primeira 
ordem mostraram-se estatisticamente significantes na relação com a "Satisfação Discente", construto de segunda ordem, conforme modelado.

Esse, por sua vez, apresenta uma relação direta e significante com o rendimento acadêmico $(\beta=0,128 ; p<0,001)$, independentemente do efeito do "Gênero", "Idade'", "Período do curso" e "Instituição de Ensino". Inicialmente, acreditava-se que havia uma relação significativa entre os cinco constructos estudados e a "Satisfação Discente", conforme modelo inicial proposto por Paswan e Young (2002), no entanto, notou-se que o constructo "Demanda da Disciplina" apresentou grande dispersão nas respostas (conforme análise descritiva realizada anteriormente), acarretando na não influência significativa desse na satisfação discente investigada. Similaridade no resultado (alta dispersão) também foi evidenciado no estudo de Beuren et al. (2013).

No mais, ressalta-se que os 4 (quatro) primeiros itens do construto "Demandas da Disciplina" demandam apontar 1 (discordo totalmente) no questionário, em caso de indícios de satisfação, enquanto que para os 2 (dois) últimos, a satisfação é capturada na marcação do outro extremo da escala (valor 5- concordo totalmente). Assim, na percepção dos presentes autores, a validade nomológica dos itens dessa escala específica precisam ser repensados, o que, possivelmente, pode ter corroborado pela não significância encontrada na relação proposta.

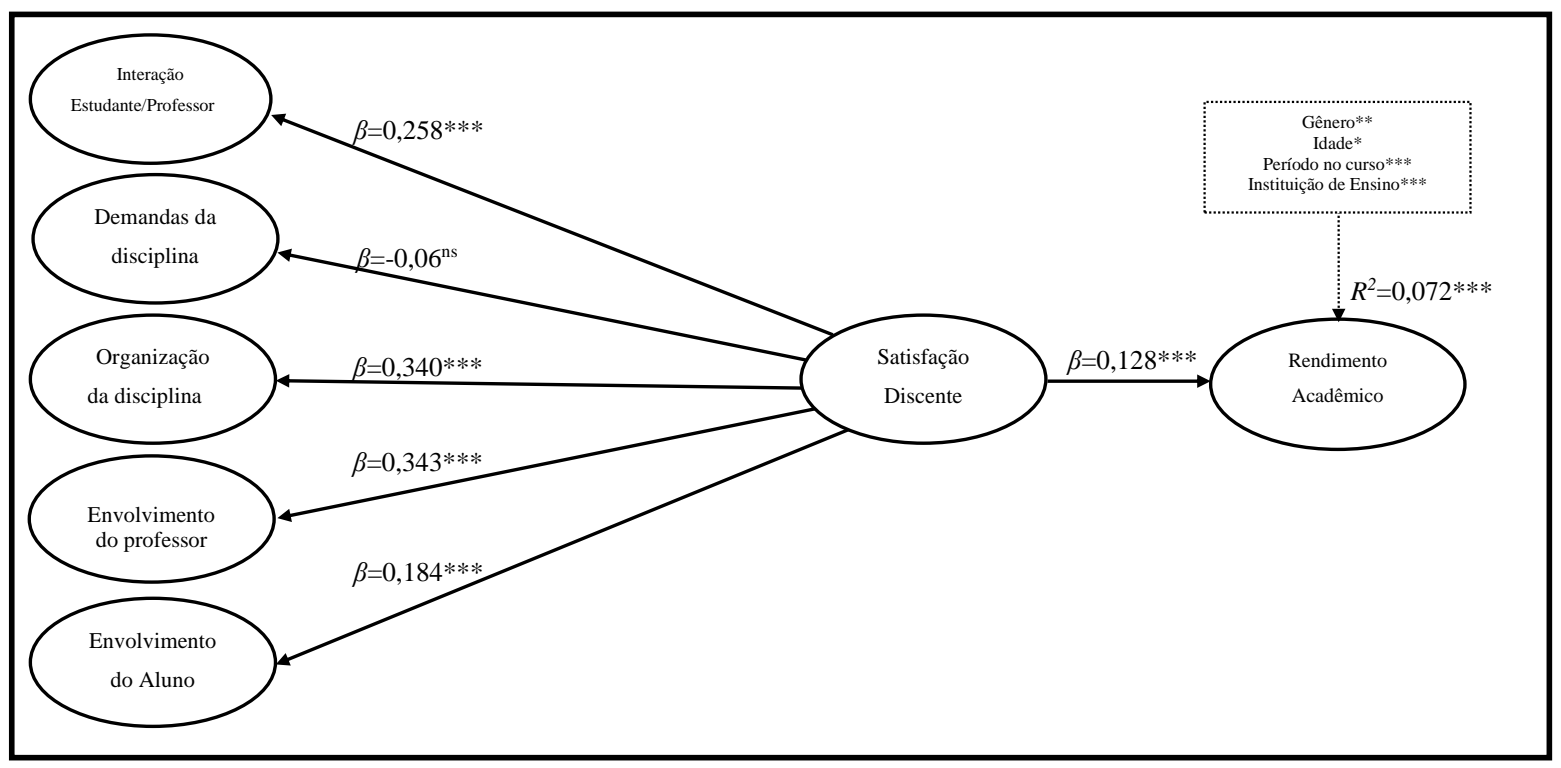

Figura 3 - Resultado do modelo estrutural proposto.

Fonte: Elaboração própria baseada nas saídas do software PLS utilizado

Onde: ${ }^{*}, * * * *$ Estatisticamente significante ao nível de 0,01, 0,05 e 0,001, respectivamente

Assim, na amostra analisada, não foi possível confirmar a hipótese de relacionamento positivo entre "Demandas da Disciplina" e "Satisfação discente". Logo, são obtidos indícios empíricos, no presente estudo, de que (pelo menos na amostra investigada) as demandas da disciplina não apresentam relação significativa na satisfação discente. Esse resultado reflete a percepção discente da existência de um nível intermediário de demandas da disciplina (atividades em sala ou extraclasse; leituras de livros e materiais suplementares, entre outros) que, no seu conjunto, mitigam o efeito previsto pela literatura. 
Ensino da Disciplina de Contabilidade Geral em Cursos de Graduação em Administração: uma Análise Empírica da Relação entre a Satisfação e o Desempenho Discente

Seguindo uma análise decrescente de impacto no construto de segunda ordem (Satisfação Discente), tem-se, incialmente, que o constructo "envolvimento do professor" mostrou-se o mais relevante, dentre os investigados, para a satisfação discente (coeficiente padronizado, $\beta=0,343$ ), resultado, este, alinhado a Paswan e Young (2002), Vieira, Milach e Huppes (2008) e Beuren et al. (2013), o que demonstra que a qualificação do professor, a metodologia utilizada e a sua postura em sala de aula influenciam direta e positivamente na satisfação discente.

Assim, são obtidos indícios empíricos que permitem confirmar $\mathrm{H}_{4}$, isto é, o envolvimento do professor impacta positivamente na satisfação discente $(\beta=0,343)$ ao nível de 0,001 . O construto "organização da disciplina" mostrou-se o segundo mais relevante à satisfação discente $(\beta=0,340)$, relacionando-se positivamente com o construto endógeno (Satisfação). Nessa perspectiva, podese afirmar que, quando a disciplina é bem planejada, os materiais são de fácil acesso, os conteúdos são apresentados de forma organizada e alinhados às expectativas dos alunos, tende-se a observar maiores níveis de satisfação discente (Paswan, \& Young, 2002; Navarro, Iglesias, \& Torres, 2005;). Diante desses resultados, a $\mathrm{H}_{3}$ é suportada, isto é, a organização da disciplina influencia positivamente a satisfação discente $(\beta=0,340)$. O constructo "interação estudante/professor" também mostrou-se positivamente relacionado à satisfação discente $(\beta=0,258)$, resultado semelhante ao observador pelas pesquisas empíricas anteriores (Paswan, \& Young, 2002; Navarro, Iglesias, \& Torres, 2005).

Esse resultado evidencia que a relação entre professor e aluno é importante, uma vez que, se que o professor é receptivo, incentiva e dar espaço para os alunos tirarem dúvidas, os discentes tendem a ter maior interesse pela disciplina e, consequentemente, maior nível de satisfação. Desse modo, corrobora-se a $\mathrm{H}_{1}$, isto é, a 'interação estudante/professor' influencia positivamente $(\beta=0,258)$ na satisfação discente.

Por fim, a categoria 'interesse do estudante' foi àquela com menor impacto, dos 4 (quatro) construtos de primeira ordem validados, na satisfação discente $(\beta=0,184)$. Mais uma vez, a relação significativa deste construto com a satisfação discente também foi identificada por Paswan e Young (2002), Vieira, Milach e Huppes (2008) e Beuren et al. (2013).

Diante disso, pode-se argumentar que o interesse do aluno pelos conteúdos, a atenção e participação destes na aula e um bom desempenho obtido na disciplina relaciona-se direta e positivamente com a satisfação na disciplina cursada, logo, quanto maior envolvimento do estudante, maior a própria satisfação com a disciplina, indicando, assim, que esses (discentes) são atores importante à própria satisfação, não devendo, nesse ponto, ser direcionado aos docentes todas as responsabilidades de eventuais insatisfações no tocante às disciplinas de Contabilidade Geral. Assim, foi observado que, das cinco categorias do modelo, quatro (Envolvimento do Professor, Interesse do Estudante, Interação Professor-Estudante e Organização do Cursol mostraram significantes para explicar a satisfação dos estudantes analisados.

Seguindo a análise do modelo estrutural, ainda conforme a Figura 3, foram notados indícios empíricos que, independentemente do efeito do gênero, idade, período no curso e tipo de instituição de ensino (pública ou privada), a satisfação 
discente (construto de segunda ordem) influencia direta e positivamente no desempenho, auto reportado, obtido na disciplina de Contabilidade Geral (ou correlata) $(\beta=0,128)$, possibilitando, assim, corroborar a $\mathrm{H}_{6}$.

Ademais, notou-se que os construtos (e variáveis de controle inseridas no modelo estrutural proposto), no seu conjunto, conseguem explicar cerca de $7 \%$ $\left(R^{2}\right)$ da variância do construto endógeno alvo, isto é, o desempenho, auto reportado, obtido na disciplina. Muito embora não exista um ponto de corte para o $R^{2}$, argumenta-se pela adequação deste coeficiente uma vez que: não era esperado um alto poder explicativo da percepção discente no desempenho, uma vez que o aprendizado efetivo requer a ocorrência de inúmeros outros fatores (como: fatores sociais, cognitivos, sociais, etc); o rendimento, auto reportado, não necessariamente reflete o desempenho efetivo nas disciplinas, acarretando, assim, eventualmente em medidas não plenamente efetivas o que, sua vez, acarreta em comedido poder explicativo por parte da percepção discente.

Segundo Nascimento e Macedo (2016), na avaliação do modelo estrutural, além de se avaliar o valor de $\mathrm{R}^{2}$ do construto endógeno, é importante investigar, também, o tamanho do efeito ( $\left.f{ }^{2}\right)$ e a relevância preditiva $\left(q^{2}\right)$ do construto exógeno no construto endógeno alvo. Assim, uma vez que foram obtidos valores de 0,391 para $f^{2}$ e de 0,395 para $q^{2}$, e ponderando os limites estabelecidos por Hair Jr. et al. (2014) de 0,02, 0,15 e 0,35 para indicar efeitos pequeno, pequeno e grande, respectivamente, conclui-se que a satisfação discente apresenta efeito de tamanho grande no desempenho auto reportada, bem como elevado nível de relevância preditiva (uma vez que os valores observados são superiores ao piso de 0,35 para ambas os casos).

Um outro relevante resultado a ser destacado ocorre no mapeamento do efeito da maturidade no desempenho acadêmico específico nas disciplinas de Contabilidade Geral. Tanto a variável de controle idade (que mostrou-se estatisticamente significante e positiva, indicando que, tudo o mais constante, quando maior a idade, maior o rendimento acadêmico), como período no curso (que mostrou-se significante e positiva, sinalizando que, com o transcorrer dos períodos letivos, os discente tendem a compreender melhor a relevância das disciplinas de Contabilidade Geral para sua formação discente), possibilitam o mapeamento indireto da maturidade tanto em termos pessoais (idade) como acadêmica (período no curso). Muito embora o interesse do estudo tenha sido apenas isolar o efeito dessa variável na relação entre "Satisfação discente" e nota média final auto reportada, esse resultado mostra-se relevante ao sinalizar pela importância de se considerar a maturidade discente em estudos correlatos.

Concluída a análise do modelo estrutural, na Tabela 2 reportam-se os resultados das hipóteses de pesquisa: 
Ensino da Disciplina de Contabilidade Geral em Cursos de Graduação em Administração: uma Análise Empírica da Relação entre a Satisfação e o Desempenho Discente

\section{Tabela 2}

Resumo dos resultados das hipóteses de pesquisa

\begin{tabular}{|c|c|c|c|c|}
\hline Hipótese & Relacionamento & $\begin{array}{c}\text { Sinal } \\
\text { Esperado }\end{array}$ & Resultado & Status \\
\hline $\mathrm{H}_{1}$ & $\begin{array}{l}\text { Interação Estudante/Professor } \quad=> \\
\text { Satisfação Discente }\end{array}$ & + & $0,258^{* * *}$ & Suportada \\
\hline $\mathrm{H}_{2}$ & $\begin{array}{l}\text { Demandas da disciplina }=>\text { Satisfação } \\
\text { Discente }\end{array}$ & + & $-0,065^{n s}$ & $\begin{array}{l}\text { Não } \\
\text { Suportada }\end{array}$ \\
\hline $\mathrm{H}_{3}$ & $\begin{array}{l}\text { Organização da disciplina => Satisfação } \\
\text { Discente }\end{array}$ & + & $0,340 * * *$ & Suportada \\
\hline $\mathrm{H}_{4}$ & $\begin{array}{l}\text { Envolvimento do professor => Satisfação } \\
\text { Discente }\end{array}$ & + & $0,343^{* * *}$ & Suportada \\
\hline $\mathrm{H}_{5}$ & $\begin{array}{l}\text { Envolvimento do Aluno => Satisfação } \\
\text { Discente }\end{array}$ & + & $0,184^{* * *}$ & Suportada \\
\hline $\mathrm{H}_{6}$ & $\begin{array}{l}\text { Satisfação Discente }=>\text { Rendimento } \\
\text { Acadêmico }\end{array}$ & + & $0,128^{* * *}$ & Suportada \\
\hline
\end{tabular}

Fonte: Elaboração própria baseada nas saídas do software PLS utilizado

Onde: *** Estatisticamente significante ao nível de 0,001 e ns estatisticamente não significante

Em suma, conforme discutido anteriormente, percebe-se que, das seis hipóteses de pesquisa investigadas empiricamente, apenas a $\mathrm{H}_{2}$, relação entre "Demandas da disciplina" e a "Satisfação Discente", não foi corroborada. Os resultados obtidos, no seu conjunto, sinalizam que, com exceção de 'Demandas da disciplina' ( $\beta=-0,060 ; \quad p<$ não significante), todos os demais construtos de primeira ordem mostraram-se relevantes para analisar a "Satisfação Discente" acerca do ensino da disciplina de contabilidade geral no curso de Administração.

Diante do exposto, são obtidos indícios empíricos de que a "Satisfação Discente" pode ser modelada como um construto de segunda ordem, formada, reflexivamente, pelos os 4 (quatro) construtos compreendidos no estudo de Paswan e Young (2002), sendo esta a primeira contribuição da presente pesquisa.

Adicionalmente, são obtidos indícios empíricos de que a "Satisfação Discente" apresenta um impacto positivo e direto no Rendimento Acadêmico auto reportado $(\beta=0,128 ; p<0,001)$, sinalizando pela importância, dado o interesse maior de maximizar o aprendizado discente, de monitorar e, sobretudo, incrementar a satisfação do aluno focando, especificamente, na melhoria do Envolvimento do Professor $(\beta=0,343)$, Organização da Disciplina $(\beta=0,340)$, Envolvimento Estudante/Professor $(\beta=0,258)$ e Envolvimento do Estudante $(\beta=0,184)$. Ressalta-se ainda que o constructo "Demandas da Disciplina" não apresentou relação positiva significativa com a "Satisfação Discente", sendo, nesse ponto, necessário repensar essa escala, no âmbito da formulação dos itens (vaidade nomológica), conforme discutido anteriormente.

\section{CONSIDERAÇÕES FINAIS}

O presente estudo buscou investigar, a partir da proposição de um modelo estrutural em que a "Satisfação Discente" é modelada como um construto de segunda ordem, a relação entre a satisfação dos alunos de graduação em Administração, acerca da disciplina de Contabilidade Geral, e o desempenho, auto reportado, obtido nesta disciplina. 
Por meio da condução de uma survey com 528 (quinhentos e vinte e oito) discentes do terceiro ao oitavo períodos dos cursos de graduação em Administração, modalidade presencial, de 7 (sete) Instituições de Ensino Superior (públicas e privadas) das cidades de Floriano-PI, Teresina-PI, Picos-PI e Parnaíba$\mathrm{PI}$ e, utilizando o instrumento de coleta de dados proposto por Paswan e Young (2002) e adaptado ao contexto brasileiro por Beuren et al. (2013), foram obtidos indícios empíricos que possibilitaram concluir pela adequação da estratégia de modelagem da "Satisfação Discente" como um construto de segunda ordem, sendo notado, para a amostra analisada, que, com exceção de "Demandas da disciplina" ( $\beta=-0,060 ; p<$ não significante), todos os demais construtos de primeira ordem mostraram-se estatisticamente significantes na relação com a "Satisfação Discente".

Por sua vez, observou-se que a "Satisfação Discente" apresenta uma relação direta e significante no Rendimento Acadêmico auto reportado $(\beta=0,128$; $p<0,001)$, independentemente do efeito do "Gênero", "Idade", "Período do curso" e "Instituição de Ensino". No seu conjunto, o construto (e variáveis de controle inseridas no modelo) conseguem explicar cerca de $7 \%\left(R^{2}\right)$ da variância do construto endógeno alvo, isto é, o desempenho, auto reportado, obtido na disciplina. O constructo "envolvimento do professor" mostrou-se o mais relevante, dentre os investigados, para a satisfação discente (coeficiente padronizado, $\beta=$ 0,343 , além da não perca de itens), sinalizando, assim, a necessidade dos docentes reforçarem o entusiasmo e envolverem-se com mais efetividade nas disciplinas de Contabilidade Geral. Em contrapartida a categoria "Demandas da disciplina" (coeficiente padronizado $\beta=-0,060$ ) mostrou-se não significante para explicar a satisfação, revertendo, assim, um relacionamento teórico esperado.

Em relação às hipóteses do estudo (modelo estrutural) que buscavam a relação dos cinco constructos de primeira ordem com a "Satisfação Discente", dentre as seis hipóteses, apenas a $\mathrm{H}_{2}$, relação entre "Demandas da disciplina" e a "Satisfação Discente", não foi corroborada, demonstrando que, na percepção da amostra analisada, a demanda da disciplina não interfere, de forma sistemática, na satisfação dos discentes com a disciplina de contabilidade cursadas. Analisando as variáveis de controle, tanto a idade (que mostrou-se estatisticamente significante e positiva, indicando que, tudo o mais constante, quanto maior a idade, maior o rendimento acadêmico), como período no curso (que mostrou-se significante e positivo, sinalizando que, com o transcorrer dos períodos letivos, os discente tendem a compreender melhor a relevância das disciplinas de Contabilidade Geral para sua formação discente), sinalizam pela importância de se considerar a maturidade, tanto em termos pessoais (idade) como acadêmica (período no curso), em estudos correlatos.

Diante dos estudos empíricos e as contribuições teóricas, os propósitos foram alcançados, visto que são reportados indícios empíricos que, no seu conjunto, possibilitam contribuir para a discussão e análise das peculiaridades e carências no ensino das disciplinas de Contabilidade no curso de Administração, possibilitando, assim, que os coordenadores e professores destas disciplinas repensem, avaliem e, sobretudo, proponham ações para a otimização do ensino destas disciplinas.

Os resultados foram coletados de forma limitada e por acessibilidade, uma vez que a amostra investigada foi compreendida por apenas 7 (sete) instituições 
Ensino da Disciplina de Contabilidade Geral em Cursos de Graduação em Administração: uma Análise Empírica da Relação entre a Satisfação e o Desempenho Discente

de ensino superior que ofertam o curso de Administração presencial em quatro cidades do estado do Piauí (Floriano, Teresina, Parnaíba e Picos), não apresentando, nesse aspecto, possibilidade de generalizações estatísticas dos resultados investigados, limitando-se, assim, aos cursos de Administração investigados. Para novas pesquisas recomenda-se que a amostra seja ampliada, incluindo mais estados brasileiros, buscando, assim, na consistência dos resultados, algum nível de generalização.

Sugere-se ainda que a percepção dos discentes de outros cursos de graduação que tenham disciplinas de Contabilidade na grade curricular, tais como Ciências Econômicas, Tecnólogo em Comércio Exterior, Turismo, Sistemas de Informação, Direito e Engenharia também sejam investigadas. Por fim, oportunidades são notadas na investigação mais profunda do impacto das "Demandas da disciplina" na satisfação discente.

\section{REFERÊNCIAS}

Abbasi, M. N., Malik, A., Chaudhry, I. S., \& Imdadullah, M. (2011). A study on student satisfaction in Pakistani universities: The case of Bahauddin Zakariya University, Pakistan. Asian Social Science, 7(7), 209. DOl: 10.5539/ass.v7n7p209.

Alves, A. C., Teixeira, V. V. N., \& Oliveira, I. G. V. (2017). Percepção dos Discentes do Curso de Graduação em Administração em Relação às Disciplinas da Área de Contabilidade. Revista Administração em Diálogo-RAD, 19(3), 24-48. DOI: 10.23925/2178-0080.2017v19i3.32551

Astin, A. W. (1984). Student involvement: A developmental theory for higher education. Journal of college student personnel, 25(4), 297-308.

Azevedo, C. E. F., Oliveira, L. G. L., Abdalla, M. M., Gonzalez, R. K., Ribeiro, A. J. G., \& Holperin, M. M. (2012). Por que Finanças?: Avaliando o interesse dos estudantes de graduação em Administração pela área de Finanças. RAM. Revista de Administração Mackenzie, 13(6), 168-196. DOI: 10.1590/S167869712012000600008

Bean, J. P., \& Bradley, R. K. (1986). Untangling the satisfaction-performance relationship for college students. The Journal of Higher Education, 57(4), 393412. DOI: $10.2307 / 1980994$

Beuren, I. M., Cunha, P. R., Theiss, V., \& Cordeiro, A. (2013). Percepção dos discentes da disciplina de contabilidade introdutória: uma análise por meio da entropia informacional em diferentes cursos de graduação. Revista de Contabilidade e Organizações, 7(19), 70-85. DOI: 10.11606/rco.v7i19.62890

Bianchi, M., Raimundini, S. L., Santos, N. D. A., Fávero, L. P. L., \& Schmidt, P. (2007). Disciplina de contabilidade introdutória: características das instituições, cursos, docentes e perfil do discente não contador. Enfoque, 29(2), 64-82. DOI: 10.4025/enfoque.v29i2.10950. 
Borges, G. F., \& Mafra, F. L. N. (2013). Ensino de contabilidade em cursos de graduação em administração: uma análise da percepção docente e discente em instituições de ensino superior de Minas Gerais. Race: revista de administração, contabilidade e economia, 12(3), 191-226.

Borges, G., F. \& Naves, F. (2014). Ensino de contabilidade na graduação em administração: uma análise sob a perspectiva discente. Revista de Contabilidade e Organizações, 8(21), 58-70. DOI: 10.1 1606/rco.v8i21.55607

Brasil. Conselho Nacional De Educação/Câmara De Educação Superior (2005) Resolução $n^{\circ}$ 4, de 13 de julho de 2005. Institui as Diretrizes Curriculares Nacionais do curso de Graduação em Administração, bacharelado, e dá outras providências. Diário Oficial da União, Seção 1, p. 26 e 27, Brasília, 19 de julho de 2005.

Brighenti, J., Biavatti, V. T., \& de Souza, T. R. (2015). Metodologias de ensinoaprendizagem: uma abordagem sob a percepção dos alunos. Revista Gestão Universitária na América Latina-GUAL, 8(3), 281-304. DOI: 10.5007/1983-4535.2015v8n3p281

Cashin, W. E. (1995). Student Ratings of Teaching: The Research Revisited. IDEA Paper No. 32.

Centra, J. A., \& Rock, D. (1971). College environments and student academic achievement. American Educational Research Journal, 8(4), 623-634. DOI: 0.1002/j.2333-8504.1970.tb00798.x

Chen, H. C., Farmer, S., Barber, L., \& Wayman, M. (2012). Development and psychometric testing of the Nursing Student Satisfaction Scale. Nursing education perspectives, 33(6), 369-373. DOI: 10.5480/1536-5026-33.6.369 Chen, T. K. (2017). Teacher-Student Relationships, Satisfaction, and Achievement among Art and Design College Students in Macau. Journal of Education and Practice, 8(6), 12-16.

Crispim, G., \& Miranda, L. C. (2013). O ensino da contabilidade no curso de administração de empresa: a percepção do corpo discente das disciplinas de contabilidade na sua formação acadêmica. ASAA-Advances in Scientific and Applied Accounting, 5(1), 131-155. DOI: 10.14392/ASAA/2012050106

Cunha, P. R., Gomes, G., \& Beck, F. (2016). Satisfação dos estudantes do curso de Ciências Contábeis: estudo em Universidades Públicas de Santa Catarina. Contabilidade Vista \& Revista, 27(1), 42-62.

da Costa, F. J., Paiva, T. A., da Rocha, J. D. A., \& Ramos, R. R. (2011). Interesse e atitudes dos estudantes de Administração em relação à área contábil. Revista de Educação e Pesquisa em Contabilidade (REPeC), 5(1), 99-120.

Fraser, B. J., Aldridge, J. M., \& Soerjaningsih, W. (2010). Instructor-student interpersonal interaction and student outcomes at the university level in 
Ensino da Disciplina de Contabilidade Geral em Cursos de Graduação em Administração: uma Análise Empírica da Relação entre a Satisfação e o Desempenho Discente

Indonesia. The Open Education Journal, 3(1). DOl: $10.2174 / 1874920801003010021$

Gomes, G., Dagostini, L., \& da Cunha, P. R. (2013). Equações estruturais aplicadas ao grau de satisfação dos estudantes do curso de Ciências Contábeis: estudo em uma faculdade do sudoeste do Paraná. Revista Brasileira de Administração Científica, 4(1), 18-32.

Hair Jr., J. F., Black, W. C., Babin, B. J., Anderson, R. E., \& Tatham, R. L. (2006) Análise multivariada de dados. Tradução de: Adonai Schlup Sant'Anna. 6. ed. São Paulo: Bookman.

Hair Jr., J, Hult, G., Ringle, C., \& Sarstedt, M. (2014). A primer on partial least squares structural equation modeling (PLS-SEM). California: Sage publications.

Iudícibus, S., \& Marion, J. C. (2000). Curso de contabilidade para não contadores. ed. São Paulo: Atlas.

Jaradeen, N., Jaradat, R., Abo Safi, A., \& Al Tarawneh, F. (2012). Students satisfaction with nursing program. Bahrain Medical Bulletin, 158(690), 1-4.

Kantek, F., \& Kazanci, G. (2012). An analysis of the satisfaction levels of nursing and midwifery students in a health college in Turkey. Contemporary Nurse, 42(1), 36-44. DOI: 10.5172/conu.2012.42.1.36

Ko, W. H., \& Chung, F. M. (2014). Teaching Quality, Learning Satisfaction, and Academic Performance among Hospitality Students in Taiwan. World Journal of Education, 4(5), 11-20. DOI: 10.5430/wje.v4n5p1 1

Lee, C. Y., White, B., \& Hong, Y. M. (2009). Comparison of the clinical practice satisfaction of nursing students in Korea and the USA. Nursing \& health sciences, 11 (1), 10-16. DOI: 10.1111/j.1442-2018.2008.00413.x

Liu, R., \& Jung, L. (1980). The commuter student and student satisfaction. Research in Higher Education, 12(3), 215-226. DOI: 10.1007/BF00976093

Naimie, Z., Siraj, S., Abuzaid, R. A., \& Shagholi, R. (2010). Did you cook your lesson based on right recipe? (Accommodating the Students Preferences in Class). Procedia-Social and Behavioral Sciences, 2(2), 383-387. DOl: 10.1016/j.sbspro.2010.03.030

Nascimento, J. C. H. B., \& da Silva Macedo, M. A. (2016). Modelagem de equações estruturais com mínimos quadrados parciais: um exemplo da aplicação do SmartPLS® em pesquisas em contabilidade. Revista de Educação e Pesquisa em Contabilidade, 10(3), 289-313. DOl: 10.17524/repec.v10i3.1376

Navarro, M. M., Iglesias, M. P., \& Torres, P. R. (2005). A new management element for universities: satisfaction with the offered courses. International Journal of 
educational management. International Journal of Educational Management 19(6):505-526. DOI: 10.1108/09513540510617454

Nérici, I. G. (2006). Metodologia do ensino: uma introdução. $2^{a}$ ed. - São Paulo: Atlas, 1981. PELEIAS, I. R. (org.). Didática do ensino da contabilidade: aplicável a outros cursos superiores. São Paulo: Saraiva.

Neves Junior, I. J. D., \& Rocha, H. M. D. (2010). Metodologias de ensino em Contabilidade: uma análise sob a ótica dos estilos de aprendizagem. Anais Encontro da Associação Nacional de Pós-graduação e Pesquisa em Administração. Rio de Janeiro, RJ, Brasil, 34.

Paswan, A. K., \& Young, J. A. (2002). Student evaluation of instructor: A nomological investigation using structural equation modeling. Journal of Marketing Education, 24(3), 193-202. DOI: 10.1177/0273475302238042

Pike, G. R. (1991). The effects of background, coursework, and involvement on students' grades and satisfaction. Research in Higher Education, 32(1), 15-30.

Ramos, A. M., Barlem, J. G. T., Lunardi, V. L., Barlem, E. L. D., da Silveira, R. S., \& Bordignon, S. S. (2015). Satisfação com a experiência acadêmica entre estudantes de graduação em enfermagem. Texto \& Contexto Enfermagem, 24(1), 187-195. DOI: 10.1590/0104-07072015002870013

Raupp, F. M., Amboni, N., Cunha, D. R., Duarte, J. F., \& Agostineto, R. C. (2009). O ensino de Contabilidade Geral e Contabilidade de Custos nos cursos de graduação em Administração do Estado de Santa Catarina. Revista de Negócios, 14(2), 71-88. DOI: 10.7867/1980-4431.2009v14n2p71-88

Santos Neto, A. S., Dantas, M. J. P., \& Machado, R. L. (2017). Structural equation modeling applied to assess industrial engineering students' satisfaction according to ENADE 2011. Production, 27.. http://dx.doi.org/10.1590/01036513.219116

Santos, A. A. A. D., Mognon, J. F., Lima, T. H. D., \& Cunha, N. B. (2011). A relação entre vida acadêmica e a motivação para aprender em universitários. Psicologia Escolar e Educacional, 15(2), 283-290. DOI: 10.1590/S141385572011000200010.

Sockalingam, N. (2012). The Relation between Student Satisfaction and Student Performance in Blended Learning Curricula. International Journal of Learning, 18(12). DOI: 10.18848/1447-9494/CGP/v18i12/47842

Souza, S. A. D., \& Reinert, J. N. (2010). Avaliação de um curso de ensino superior através da satisfação/insatisfação discente. Avaliação: Revista da Avaliação da Educação Superior (Campinas), 15(1), 159-176.

Vasconcelos, N. P. (2000). Uma contribuição para a melhoria da qualidade do ensino em Ciências Contábeis - uma abordagem sistêmica. Revista Brasileira de Contabilidade, Brasília, 125, 30-36. 
Ensino da Disciplina de Contabilidade Geral em Cursos de Graduação em Administração: uma Análise Empírica da Relação entre a Satisfação e o Desempenho Discente

Vieira, K. M., Milach, F. T., \& Huppes, D. (2008). Equações estruturais aplicadas à satisfação dos alunos: um estudo no curso de ciências contábeis da Universidade Federal de Santa Maria. Revista Contabilidade \& Finanças, 19(48), 65-76. DOI: 10.1590/S1519-70772008000300006 